Revista de Psicología de la PUCP. Vol. XV, 1, 1997.

\title{
LA SABIDURIA COMO ESCEPTICISMO MODERADO: CAMBIOS DURANTE EL CURSO DE LA VIDA ${ }^{1}$
}

\author{
Gerard M. Brugman ${ }^{2}$ \\ Universidad de Utrecht. Países Bajos
}

La sabiduría es analizada en términos de la tradición escéptica griega. Es crucial para la sabiduría el reconocimiento de la incapacidad para adquirir conocimiento infalible y la aceptación de actuar en el mundo tomando como referencia el conocimiento falible. Este se basa en la noción de lo plausible. La epistemología falibilística es útil para la pragmática de la vida, que es un campo donde los problemas están particularmente mal definidos. Se asume que la sabiduría es una función de la cultura y la historia: primero como un contenido y luego como un concepto más cognitivo. Es decir, la sabiduría ha evolucionado históricamente de una capacidad cognitiva a una metacognitiva. Con respecto a los cambios en la sabiduria a lo largo de la vida, se argumenta que éstos no están relacionados con la edad. Finalmente, se asume que los cambios en la sabiduría están en función de cómo se lidia con los eventos de la vida, de la acumulación de conocimientos, del desarrollo cognitivo y de la personalidad. Palabras claves: sabiduría, escepticismo, cognición

Wisdom as moderate scepsis changes over the life-span

Wisdom is analyzed in terms of the Greek sceptic tradition. Crucial for wisdom is the acknowledgment of the inability to acquire infallible knowledge and the acceptance to act upon the world on the basis of that same fallible knowledge. This fallibilism is based on the notion of the plausible. This fallibilistic epistemology is useful in the domain of life pragmatics, notably a domain of ill-defined problems. It is assumed that the nature of wisdom is a function of culture and history: first as a content and then to a more cognitive style concept. This means that wisdom has historically evolved from a cognitive to a metacognitive capacity. With respect to changes in wisdom over the life span it is argued that in contrast to the communis opinio, these changes are not age-related. Finally, it is assumed that changes in wisdom are a function of dealing with life-events, the accumulation of knowledge, cognitive development and personality.

Key words: wisdom, sceptisim, cognition

1. Artículo traducido por Carlos Iberico y revisado por Carmen Lazaite.

2. Profesor Asociado en el Departamento de Pśicología del Desarrollo. Correo electrónico: G.Brugman@fsw.ruu.nl. 
Si no hay alimento para la sabiduría en el libro de los sabios, ¿dónde ha de encontrarse entonces?

Nicolás de Cusa, 1450

La cita proviene del "Idiotia de sapientia" de Nicolás de Cusa, filósofo y prelado del siglo XV. Es una clase de pregunta retórica hecha por un hombre de libros, defendiéndose de un hombre analfabeto, un "idiotia", quien duda del valor de la ciencia en la búsqueda de la sabiduría. El argumento desbaratador del idiotia implica que la sabiduría podría encontrarse en los libros, aunque no en su forma pura y natural; mientras que los primeros escritores sobre sabiduría no la podían extraer de los libros porque no existían por ese entonces...

Este artículo no intenta ser un "libris sapientia". Su propósito es sólo ofrecer un modelo heurístico de la naturaleza de la sabiduría y de sus cambios a lo largo de la vida, partiendo de la escasa aunque vertiginosamente creciente actividad científica en este campo. Toda esta actividad no ha conducido, sin embargo, a un cuerpo coherente de conocimientos sobre la naturaleza y cambios de la sabiduría a lo largo de la vida. Como la sabiduría puede situarse en el nexo de la filosofía y la psicología, las ideas presentadas en este artículo se derivan de ambas disciplinas. La filosofía, principalmente para la parte conceptual y la psicología, para las preguntas que conciernen a los cambios relacionados posiblemente a la edad durante el curso de la vida.

Existen algunas preguntas que pueden formularse cuando se discute acerca de la sabiduría: ¿por qué existen algunas personas sabias? y/o ¿se atribuye sabiduría a algunos y no a otros?; ¿ cuáles son los determinantes de los cambios en la sabiduría a lo largo de la vida?; ¿existen cambios en 
la sabiduría con la edad o diferencias en la sabiduría entre grupos de edad?; y si es así, ¿estos cambios y/o diferencias son de naturaleza evolutiva o no?, ¿pueden discernirse las diferencias culturales concernientes a estas interrogantes? ¿existen diferencias grupales?, ¿pueden discernirse los cambios históricos en la naturaleza de la sabiduría y el rol de ella en la sociedad? En realidad, un tonto puede formular más preguntas que las que diez sabios pueden responder. Todas merecen un serio escrutinio pero sólo a algunas de ellas se les ha prestado cierta atención teórica y aún menor atención empírica.

En esta contribución, trataremos de abordar sólo dos de las muchas preguntas que pueden hacerse. Centraremos nuestra atención en los siguientes temas de importancia: la naturaleza de la sabiduría a la luz de la filosofía helenística, especialmente la filosofía escéptica de Carneades; y el desarrollo de y/o cambios en la sabiduría a lo largo de la vida. Se presta, además, alguna atención a aspectos históricos y culturales de la sabiduría.

\section{La naturaleza de la sabiduría}

La portada del De Verulanio Historia Regni Henrici Septimi de Francis Bacon, publicado en 1642 en Leiden, muestra un grabado en aguafuerte hecho por Cornelis van Dalen (Figura 1). El grabado representa a la Fortuna y su rueda, rodeada por cuatro hombres. Tres de ellos son aduladores tratando de complacer a la Fortuna. El cuarto hombre sólo sostiene la rueda utilizando para este propósito la lanza de uno de los aduladores, que es un soldado absorto en hacer una reverencia. Se considera a este cuarto hombre como el sabio. Quienes merecen el epíteto de "sabios" no son aquellos cuyos modos de actuar se orientan al cambio y la innovación los aduladores tratan de cambiar su destino pidiéndole favores a la Fortuna- sino, más bien, aquellos otros cuyos modos de actuar buscan la integración y la adaptación. La sabiduría implica tener todo bajo control, a pesar de los caprichos de la fortuna. En sus diálogos, Séneca (1996) describe al sabio como alguien que es inmune a la injusticia; no importa cuántos proyectiles le disparen, ninguno lo alcanzará. Esta invulnerabilidad a los cambios en la fortuna puede encontrarse también en los Cínicos 
La sabiduría

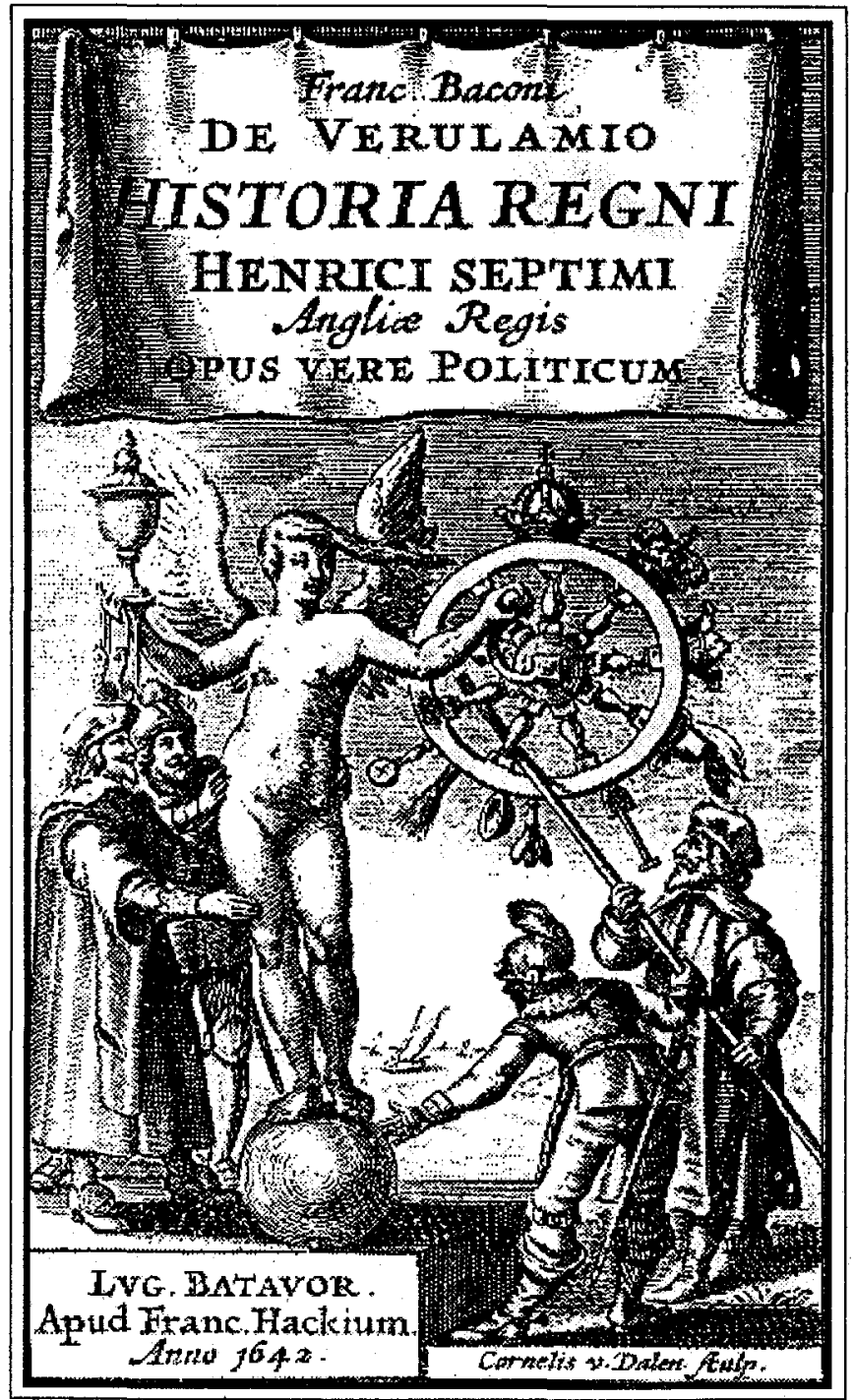

Figura 1

La Fortuna y los aduladores 
aunque de un modo más extremo (Long, 1986). Esto implica asumir una posición intermedia entre la perspectiva epicúrea, que sostiene que la paz de la mente se gana liberando la voluntad de las leyes de la naturaleza y la perspectiva estoica, que sostiene que la paz de la mente proviene de someterse a esas leyes (Cicerón, 1994).

Tal invulnerabilidad también es ejemplificada por el emblema encontrado en los siglos XVI y XVII. La sabiduría es representada allí como una piedra cuadrada que cuando es lanzada, siempre cae sobre su base (Henkel y Schone, 1967):

\section{"Del Alma Sabia"}

Uno no puede mostrarse más sensato y sabio/ que cuando soporta todo tal como va llegando, sea dicha o desdicha/ con un ánimo completamente igual, no dejándose superar por ellas/ sino más bien separándolas con calma y ecuanimidad/, lo cual encaja con la alegoría de una piedra cuadrada: el ánimo sabio se muestra entonces como esa piedra/ se puede voltear y tirar/ adonde se lance siempre cae sobre su base/ por así decirlo/ cae bien y permanece en su depósito... (p. 71).

Esta aptitud específica de tenerlo todo bajo control está relacionada, si no producida, con una actitud específica hacia el conocimiento: la postura epistemológica específica que resulta puede ser caracterizada como una forma moderada de escepticismo: falibilismo o probabilismo. Este falibilismo puede concebirse como el corazón de la sabiduría. Se trata de una actitud específica hacia lo que es cognoscible y hacia la justificación del conocimiento.

Tal actitud puede especificarse aún más. Con respecto a la cognoscibilidad del mundo pueden asumirse diversas posiciones que varían en función de lo que uno cree conocer y de lo que uno piensa que se puede conocer (Meacham, 1983; Brugman, 1994). Esto concierne a la proporción percibida de lo que uno cree que posiblemente puede conocerse. $Y$ justamente es esa proporción, y no lo que uno cree conocer como tampoco lo que uno 
piensa que posiblemente puede conocerse -vistos separadamente- la que codetermina el grado de certidumbre. Codetermina porque existen otros factores que también podrían ser importantes al determinar la ubicación del individuo en el continuo de certidumbre y duda. A este respecto, se puede pensar en factores como el desarrollo cognitivo y la personalidad; por ejemplo, la tolerancia a la ambigüedad y la efectividad percibida de los conocimientos que uno posee para predecir resultados. Por supuesto que la efectividad percibida no coincide necesariamente con la validez.

Con relación a la sabiduría, una ubicación plausible en la dimensión de la certidumbre y la duda podría justo encontrarse en el punto medio de ambos extremos (Brugman, 1994a, 1994b; Meacham, 1983, 1990;). Demasiada certidumbre es tan poco aconsejable como demasiada duda puesto que ambas podrían dar paso a respuestas emocionales y conductuales poco adaptativas como, por ejemplo, la rigidez y la inercia. Debe darse tanto el percatamiento de las limitaciones del conocimiento como el reconocimiento de la necesidad de actuar en el mundo. Es como una canción de Billy Holiday, que dice: "Si eso no es amor, tendrá que serlo hasta que el verdadero venga". Se trata de una postura pragmática en la que se acepta la incertidumbre aunque sin la consecuencia final del epoché eterno o la suspensión del juicio. Como veremos posteriormente, Carneades, el escéptico académico del siglo II A.C., reconociendo la falibilidad humana, sugirió sólo esto: deberíamos ser guiados por lo que es probable. Es, justamente, en este argumento que radica la diferencia entre Carneades y Meacham. No es la ubicación del individuo entre la certidumbre y la duda como tal, sino el hecho de que el mismo individuo pueda actuar y juzgar en presencia de la duda. Actuar y juzgar como si las cosas fueran más o menos ciertas por razones pragmáticas.

En relación a la justificación del conocimiento obtenido, la sabiduría puede caracterizarse por el empleo de la justificación probabilística, una noción que también podemos encontrar en Carneades. Esta clase de justificación implica el uso de evidencias y argumentos que se basan en criterios generalizables (Kitchener, 1983). Se hipotetiza que este equilibrio epistemológico tiene implicancias de mayor alcance dentro del campo de 
la pragmática de la vida, es decir, el campo de los problemas que pertenecen a los dominios jasperianos de sufrimiento, muerte, oportunidad, culpa y lucha. Puede influir sobre nuestras acciones y emociones, sobre nuestra percepción del control de los eventos de vida y sobre las estrategias de afrontamiento.

$\mathrm{Y}$ al dar al individuo los medios necesarios, puede considerarse como un determinante importante de satisfacción de vida, esto es, de los éxitos y fracasos percibidos en la vida.

Con respecto a la emoción, el equilibrio epistemológico puede dar paso a la metriopatheia:, que es la moderación del afecto, que puede concebirse como una posición intermedia entre el compromiso emocional total y el desapego. En cuanto a la acción, puede inhibir la acción directa y evitar la inercia. Debe enfatizarse que tanto la emoción como la acción se consideran derivados de la posición epistémica que personalmente uno sostiene (ver también Birren [Sternberg, 1990]). Asimismo, esta actitud específica hacia el conocimiento puede influir en el control percibido de los eventos. Como se afirmó anteriormente, se supone que las personas sabias lo tienen todo bajo control. Esto significa que ellas sacan el mejor partido de cada una de las circunstancias que enfrentan. En términos del control percibido, se ubican en una posición intermedia en cuanto al control personal; es decir, existe una proporción adecuada entre el control heterónomo y el autónomo. Ellas dan crédito a la influencia tanto de factores externos como de factores personales sobre la causa y los efectos de los eventos (Brandstater y Baltes-Gotz, 1993; Gatz y Karel, 1993). En consecuencia, ni sobrestiman ni subestiman la influencia de ambos factores. Estas percepciones de control se relacionan con el modo en que el individuo lidia con sus problemas en el campo de la pragmática de la vida. $\mathrm{El}$ individuo alternará adecuadamente entre la "respuesta de meta tenaz (o firme)" y el "ajuste de meta flexible" (Brandstater \& Baltes-Gotz, 1993), esto es, entre la asimilación y la acomodación. Intenta arduamente alcanzar las metas personales pero éstas son modificadas cuando el cambio resulta inevitable. Esto es bastante diferente al adagio estoico que propone reconciliar lo inevitable ya que el mismo conlleva una carga más pasiva. 
Tanto el control como el éxito percibidos son variables decisivas para la forma en que los individuos estructuran sus vidas. Así, el equilibrio epistemológico puede constituirse también, directa o indirectamente, en un determinante importante de la estructuración de la vida. Frye (Harré, 1985) distingue cuatro estructuras dramáticas utilizadas como metáforas: la comedia, el romance, la tragedia y la sátira (ver Cuadro 1 y Figura 2).

Estas estructuras narrativas pueden dar significado a eventos aislados en la vida de cada quien; y el repaso de la vida para dotar de significado al pasado de uno constituye un importante dominio de la sabiduría (Baltes \& Smith, 1990; Dittmann-Kohli, 1990; 1995). La naturaleza de estas narrativas es una función del control y el logro percibidos. Dado que la sabiduría implica equilibrio epistemológico, el cual se asocia a un nivel medio de control personal, las estructuras narrativas que más probablemente están ligadas a la sabiduría son la comedia y la sátira. La dimensión de logro, vinculada al éxito o fracaso percibidos en la vida, parece apuntar a la comedia como la estructura "apropiada" para el sabio. Sin embargo, al analizar más cuidadosamente la naturaleza de la narrativa satírica, aparece una nueva hipótesis: la narrativa satírica o irónica describe el fracaso como: ".....el fracaso, a pesar de estar dentro del héroe el poder evitarlo....." (Murray, 1985, p. 179)

Esto abona fuertemente a favor de la narrativa satírica como la estructura más sabia. Con todo, el asunto debe ser establecido empíricamente. Otra posibilidad es asumir la existencia de más de una forma de sabiduría. Este punto de vista corresponde con la noción de sabiduría propuesta por Assmann (1990; 1994), la cual es definida como un concepto multidimensional. Regresaremos a este tópico más adelante.

En resumen, se podría considerar a la sabiduría como una clase de estilo metacognitivo que permite un afrontamiento adaptativo y flexible de las incertidumbres: actuar a pesar de la incertidumbre.

Con el fin de elaborar mejor este estilo metacognitivo, tenemos que examinar con mayor detalle la epistemología escéptica. 


\section{Cuadro 1}

Parámetros de las estructuras narrativas y variantes de la sabiduria (Murray, 1985; Brandsfädter y Baltes-Götz, 1993; Assmann, 1994; Brugman, 1995)

\begin{tabular}{|l|l|l|l|l|}
\hline & comedia & ronance & tragedia & stíra \\
\hline Logro percibido & éxito & éxito & fracaso & fracaso \\
Control percibido & medio & alto & bajo & medio \\
Soluciones & reconciliación & esperanza & desesperación & ironía \\
Red/Grupo & colectivo & formal & individual & informal \\
Filosofía & pragmatismo & idealismo & fatalismo & existencialismo \\
Postura epistémica & falibilismo & dogmatismo & dogmatismo & falibilismo \\
Tipo de sabiduría & Polonio & Salomón & Próspero & Jacques \\
\hline
\end{tabular}

Figura 2

Narrativas de vida como una función de la percepción de control y de logro. (Brugman, 1995)

\begin{tabular}{|l|l|}
\hline Control personal & Control personal \\
\hline alto control autónomo/ & $\begin{array}{l}\text { alto control autónomo/ } \\
\text { alto control heterónomo: } \\
\text { bajo control heterónomo: } \\
\text { alto control personal } \\
\text { narrativa }\end{array}$ \\
$\begin{array}{l}\text { control personal medio } \\
\text { narrativa }\end{array}$ \\
\hline cómica
\end{tabular}




\section{La sabiduría y los escépticos}

Los filósofos escépticos, desde Pirrón, rara vez se ocuparon explícitamente de los sabios y de la sabiduría. Su principal tópico de interés tuvo que ver con los problemas epistemológicos (Hankinson, 1995; Honderich, 1995; Lehrer, 1990; Long, 1986; Long \& Sedley, 1992; McKiharan, 1994; Sixto Empírico, 1994). Aún así, su filosofía ofrece varias referencias sobre la sabiduría.

El término "escepticismo" se deriva de skeptesthai, que implica encontrarse permanentemente en un estado de búsqueda de la verdad, aunque jamás se llega a encontrarla'. Cioran (1995) señala exactamente esta característica cuando critica la posición dogmática:

No me cabe ninguna duda que la sabiduría es el fin principal de la vida y es por ello que regreso siempre a los estoicos. Ellos alcanzaron la sabiduría y, en consecuencia, no se les puede llamar más filósofos en el sentido propio del término. Desde mi punto de vista, la sabiduría es el término natural de la filosofía, es su fin en los dos sentidos de la palabra. Una filosofía termina en sabiduría y por lo mismo desaparece (1995, p. 1780).

Por lo tanto, los escépticos también fueron conocidos como Zetéticos. Un sceptikos es alguien que mira o examina. Heráclito (nacido 540 años A.C.) lo formuló de la siguiente manera: "Los hombres amantes de la sabiduría deben ser en realidad inquisidores de muchas cosas" (Cohen, Curd \& Reeve, 1995, p. 27).

Pirrón de Elis (360 - 270 A.C.) puede ser considerado como el padre fundador del escepticismo aún cuando él ni fundó una escuela ni dejó texto escrito alguno. Lo conocemos a través de los escritos de sus discípulos Timón, Aenesidemos y Numenio. Unos quinientos años más tarde, Sixto Empírico (200 A.C.) hizo una importante contribución al escepticismo

1. Aunque existen diversas teorías de la verdad, como las de correspondencia, de coherencia, de acuerdo y las pragmáticas, aquí, la verdad denota correspondencia con la realidad. 
pirronista: su Bosquejos del Escepticismo, que constituye en realidad nuestra principal fuente para la epistemología de Pirrón. La obra fue un homenaje al escepticismo radical de Pirrón y asimismo un ataque a los Dogmáticos, especialmente a los Estoicos aunque también a la Academia Escéptica (Sixto Empírico, 1994). El escepticismo de Pirrón es radical, sostiene que la duda absoluta conduce necesariamente a la epoché o suspensión del juicio y es por eso que a los escépticos se les conoce a veces como Efécticos. Esta epoché se basa en la noción de isosthenenia (equipotencia o poder similar de los argumentos), la cual produce un estado de adoxastos, esto es, de encontrarse sin opinión. La meta final era la ataraxia o estar libre de perturbaciones, un objetivo también buscado por escuelas contrarias de la filosofía helenista; por ejemplo, los estoicos, aunque con medios completamente diferentes. Los pirronistas argumentaban que no tener opiniones era una garantía para la tranquilidad de la mente, si uno no tiene opiniones definidas, no puede ser sacudido por información contradictoria o puntos de vista opuestos. Aunque suena lógico, este argumento parece ser contraintuitivo en vista de la necesidad de control o la motivación de competencia, que se supone son fundamentales en los seres humanos (ver Seligman, 1967; White, 1959); no tener opiniones definidas implica ser incapaz de predecir los resultados de nuestras acciones. Retomaremos esta objeción más adelante.

Sixto Empírico, una fuente importante para conocer el escepticismo de Pirrón, caracterizaba a los escépticos, al contrastarlos con los dogmáticos y los académicos, como sigue:

Aquellos que son llamados Dogmáticos, en el sentido propio de la palabra, piensan que han descubierto la verdad; por ejemplo, las escuelas de Aristóteles, Epicúreo, los Estoicos y algunas otras más. La escuela de Clitomaco, Carneades y otros Académicos sostiene que las cosas no pueden ser aprehendidas y los Escépticos todavía se encuentran investigando (1994, p. 3).

Esta afirmación de Sixto Empírico soslaya, sin embargo, un elemento importante en la teoría epistemológica de Carneades (214-129 A.C.), una 
de las figuras descollantes de la Nueva Academia; este elemento es la noción de lo probable. Desafortunadamente, al igual que Pirrón, Carneades no dejó ningún texto escrito. Un discípulo escribió $\mathbf{4 0 0}$ libros de argumentos pero sólo sobrevivieron algunos informes parafraseados. Lo que sabemos de él, se debe en parte a Cicerón (Long, 1986). Se dice que, en cierta ocasión, Carneades dio un discurso en Roma a favor de la justicia mientras que al día siguiente, defendió exactamente el punto de vista contrario y por eso Catón lo expulsó de la ciudad (Honderich, 1995; p. 122).

Carneades, director de la Academia de Platón, (Hankinson, 1995; Honderich, 1995) sostenía que la certidumbre era imposible y como Pirrón era partidario del epoché. Con relación al alcance del concepto epoché, Carneades afirmó, sin embargo, que "los seres humanos no pueden en realidad suspender el juicio en torno a todas las cosas; no tienen necesidad de hacerlo en ningún caso" (Hankinson, 1995, p. 96). La diferencia entre Carneades y Pirrón radica en sus diferentes posiciones respecto de los ejes ontológico y epistemológico del escepticismo. A nivel ontológico, Carneades es un verdadero escéptico al no saber si existe un mundo real mientras que a nivel epistemológico, es un dogmático negativo, al negar la posibilidad de obtener un conocimiento confiable acerca del mundo. De otro lado, Pirrón era un genuino escéptico en ambos niveles: deja abiertas las interrogantes de la existencia real del mundo y de la posibilidad de obtener conocimiento confiable sobre el mismo, aún cuando su posición respecto del nivel ontológico tiende hacia un dogmatismo positivo; en otras palabras, hacia la idea de un mundo realmente existente (Hankinson, 1995). De hecho, la teoría de Carneades es probabilística y trata de mitigar tanto el pirronismo como el dogmatismo (Honderich, 1995). Carneades abandonó el escepticismo estricto y lo reemplazó por el falibilismo. Sostenía que deberíamos ser guiados por lo probable, aunque no en el sentido estadístico sino en el sentido de algo aprobable o persuasivo. Cicerón, una de las principales fuentes de la teoría de Carneades, afirma que probabile se refiere a las impresiones sensoriales que son persuasivas o fidedignas y las describe de la siguiente manera: 
Así, el hombre sabio hará uso de cualquier presentación aparentemente probable que encuentre, si es que no se presenta nada contrario a esa probabilidad, y todo su plan de vida será trazado de esta manera (Cicerón, 1994, 99, p. 595).

A pesar que la descripción no es impermeable, en la vida diaria podemos juzgar y actuar eficazmente con un criterio de grados de confiabilidad (Long, 1986). Algo afín puede encontrarse, casi dos milenios más tarde, en los escritos de Pierce y Popper. Aquí, se permite un amplio rango de opiniones y si bien ellas podrían resultar falsas, de todas maneras pueden ser consideradas como aproximaciones a la verdad (Long \& Sedley, 1992; Martelaere, 1996). Como se mencionó anteriormente, creemos que esto constituye el núcleo de la sabiduría, juzgar y actuar sobre la base de aproximaciones a la verdad. Ello implica lidiar con la incertidumbre y se supone que los sabios son expertos en este campo. El empleo del término "verdad", que denota correspondencia con la realidad, no implica sin embargo la presunción de que la verdad puede alcanzarse alguna vez. La aproximación a la verdad tan solo implica un movimiento en dirección del horizonte hipotetizado y ha de ser considerada como un dispositivo heurístico. Para utilizar la cita de Cicerón:

...ni tampoco abandonaremos por agotamiento nuestro fervor por la investigación y el único objeto de nuestras discusiones es contrapesar los argumentos de ambos lados para extraer y dar forma a algún resultado, que puede ser la verdad o la aproximación más cercana a la verdad (1994, p. 475).

En cualquier caso, el falibilismo soluciona el problema ocasionado por el escepticismo estricto; es decir, la paradoja escéptica: el escepticismo destruye al escepticismo. Así, Anaxarco de Abdera enseñaba que él ni siquiera sabía que no sabía. Para citar a Wittgestein: "Quien quiera dudar de todo, no llegaría tampoco hasta la duda. El mismo juego de dudar presupone ya la sabiduría" (1969, p. 18).

En realidad, Wittgestein acusa a los escépticos de transgredir las reglas de juego del lenguaje (Long \& Sedley, 1992). El escepticismo radical no 
es posible porque en ese caso, uno tiene que dudar también de las palabras en las que se expresa la duda: "El que no está seguro de ningún hecho tampoco puede estar seguro del sentido de sus palabras" (Wittgenstein, 1969, p. 17).

Los mismos escépticos ofrecieron varias soluciones a esta paradoja. Así, Sixto Empírico asume que el escepticismo funciona como una medicina purgante; no sólo drena los humores del cuerpo sino también se expulsa junto con los humores (1994). Y de acuerdo a Hume, simplemente carecemos de la capacidad mental para proseguir con nuestras reflexiones de un modo ad infinitum (Norton, 1993). Sin embargo, el falibilismo escabulle el problema, pudiéndose considerar su propia teoría tan solo como una aproximación a la verdad. Además, el falibilismo ofrece una base sólida para juzgar y actuar apropiadamente sin necesidad de axiomas fijos, sean sobre la cognoscibilidad del mundo o sobre la existencia del mundo. Es una actitud útil y práctica hacia el mundo y hacia su conocimiento.

\section{La sabiduría y el pensamiento postformal}

Aunque los filósofos tienen una larga tradición con respecto a la sabiduría, los psicólogos también la han abordado. Existe una "escuela" que posee una rica tradición en los temas relacionados a la sabiduría, la de los neopiagetanos.

En el enfoque neopiagetano relacionado al desarrollo cognitivo (adulto), una de las presunciones es la existencia de un quinto estadio en el desarrollo cognitivo denominado de operaciones postformales. Las numerosas conceptualizaciones de este estadio generalmente manifestadas en términos más bien imprecisos, son sorprendentemente similares a las conceptualizaciones de la sabiduría; en realidad, esto es más que una similitud coincidente. Ambas tienen que ver con los problemas interpersonales en el campo de la pragmática de la vida y ambas se conciben como una manifestación superior, si no la más alta posible, de las operaciones cognitivas. Así, las descripciones del pensamiento como relativista, dialéctico, unitario o transparadigmático, son comparables a aquéllas de la sabiduría. 
Una de las críticas relacionadas a la epistemología genética original de Piaget tiene que ver con la hipótesis del desarrollo máximo en la adolescencia, el periodo formal, que se refiere al pensamiento hipotético-deductivo y se supone que es la fase más avanzada del desarrollo cognitivo que puede alcanzarse en la adolescencia, aún cuando no todo adolescente ni siquiera todo adulto, llegan a ella. Así, las operaciones formales representan el cenit del desarrollo cognitivo. Sin embargo, de acuerdo a los neopiagetanos, existen varios argumentos en contra de tal hipótesis (Commons, et al,1990; Labouvie-Vief, 1985; 1990). Mencionamos dos de ellos, el pensamiento formal se ajusta a la lógica simple mientras que muchos problemas de la vida, al estar mal definidos y ser interpersonales por naturaleza, no pueden ser resueltos mediante un razonamiento lógico simple. Además, es muy improbable que el desarrollo cognitivo llegue a su fin en la adolescencia o en la adultez temprana. Si bien la hipótesis del desarrollo máximo en la adolescencia tiene alguna validez aparente, a decir verdad es una forma de incurrir en una petición de principio.

Sin embargo, debe destacarse que Piaget, tal como Laurenco y Machado (1996) han hecho notar recientemente, ya desde 1955 (Piaget e Inhelder) afirmaban que: "...la estructura de las operaciones formales no se modifica durante el curso de la vida del individuo aunque puede integrarse a sistemas mayores, tales como las lógicas polivalentes" (p. 295).

El postulado general de la investigación que estudia la relación entre pensamiento formal y pensamiento postformal es que el primero no es un prerrequisito para el segundo. La investigación indica que el pensamiento postformal no es una fase superior, más poderosa, del desarrollo cognitivo (Arlin, 1975; Chandler y Boutilier, 1992; Kallio y Helkama, 1991; Kitchener y Brenner, 1990; Kitchener y King, 1981; Linn y Siegel, 1984; ). De esta manera, el pensamiento postformal puede constituir una forma paralela de cognición, no una diferente ni ciertamente una fase superior del desarrollo cognitivo. Su naturaleza puede ser práctica, meta-reflexiva y contextual. Así que lo más seguro sería asumir un posición discreta y concebir el pensamiento postformal como un estilo metacognitivo. 
Ahora bien, existen varios problemas serios con el enfoque neopiagetano, el carácter tipo-estadio de los cambios cognitivos en la adultez es cuestionable y más importante que eso, no hay consenso sobre la naturaleza concreta de las operaciones postformales (Arlin, 1975; Commons et al, 1990; Kitchener, 1983; Laurenco \& Machado, 1996; Riegel, 1973).

Sin duda, existen algunas características comunes en las operacionalizaciones del pensamiento postformal: la aceptación del relativismo y la contradicción; la integración de marcos de referencia; y el pragmatismo (Sinnott, 1984). El pensamiento postformal implica el reconocimiento de la coexistencia de diversos sistemas que, siendo lógicamente consistentes entre sí, son al mismo tiempo mutuamente excluyentes (ver, por ejemplo, Labouvie-Vief, quien designa al pensamiento postformal como operaciones intersistémicas, $1985 ; 1992)$.

Una teoría neopiagetana que merece especial atención es el enfoque dialéctico de Riegel sobre el desarrollo cognitivo. Riegel se aparta de las presunciones piagetanas originales de tres maneras. Primero, añade un quinto estadio al cual denominó como dialéctico; esto es, un estadio en el que el individuo: "es capaz de aceptar las contradicciones como la base de todo pensamiento y de tolerar las operaciones conflictivas, sin equilibrarlas en todas las circunstancias" (Riegel, p. 61).

Segundo, él asume que los estadios se superponen entre sí: los individuos pueden operar en niveles diferentes, dependiendo de la naturaleza de la tarea que ellos enfrenten. No obstante, la diferencia más importante es su presunción en el sentido de que en cada estadio existe la posibilidad de desarrollar una dimensión específica de estilo cognitivo, caracterizada como dialéctica. Así, al desechar la cuestionable presunción de un estadio dialéctico separado, cada estadio puede manifestarse a sí mismo de un modo dialéctico. Y como el modo dialéctico es análogo a la sabiduría, según se dijo anteriormente, lo que ello implica es que la sabiduría puede manifestarse a lo largo de la vida aunque en diferentes niveles.

La relación de la sabiduría con el pensamiento postformal es también visible en el hecho de que ambos pertenecen al campo de la pragmática 
de la vida; ambos se refieren a la capacidad para hacer juicios acertados con respecto a asuntos importantes de la vida, los cuales comprenden su revisión, manejo y planeamiento. Contrariamente al dominio de los problemas bien definidos en donde se supone que los pensadores formales son expertos, tanto los problemas en sabiduría como aquellos en operaciones postformales están generalmente mal definidos: el problema mismo tiene todavía que ser formulado, la naturaleza de la solución no es clara como tampoco lo es la forma de llevarla a cabo. La operacionalización que Arlin (1975) hace de las operaciones postformales, como que implican el descubrimiento del problema, simplemente acentúa tal aspecto. $Y$ al igual que el pensamiento postformal, la sabiduría puede ser concebida como destreza en la incertidumbre, teniendo como base una actitud epistemológica específica. Hay que enfatizar, sin embargo, que existen muchas otras conceptualizaciones (Sternberg, 1990). La conceptualización que habla de destreza en la incertidumbre pertenece a la epistemología. En diversas teorías, es el conocimiento con respecto a la pragmática de la vida lo que se considera como núcleo de la sabiduría.

Este énfasis en el conocimiento como núcleo de la sabiduría puede encontrarse, por ejemplo, en Assman (1994). Ella distingue cuatro aspectos en la sabiduría y todos se refieren al conocimiento, especialmente el primero:

- extensión: la sabiduría implica conocer más

- profundidad: la sabiduría implica conocer más profundamente

- difícil accesibilidad: la sabiduría implica conocer lo que está más allá del alcance de una persona común y corriente, y

- edificabilidad: la sabiduría implica conocer lo que es bueno para sí mismo y los demás.

Muy común a diversas concepciones sobre sabiduría es el mayor énfasis que ponen en el producto, respecto del proceso. Hay, con todo, algunas excepciones; como, por ejemplo, la investigación sobre juicio reflexivo de Kitchener (1983). Regresaremos a los neo-piagetanos cuando lleguemos al parágrafo sobre los cambios en la sabiduría a lo largo de la vida. Sin embargo, ese enfoque orientado al proceso no se encuentra solamente en 
la tradición neo-piagetana: la contribución teórica de Meacham (1983; 1990) también tiene que ver con el proceso y no con el producto. Como se señaló anteriormente, en la teoría de Meacham la sabiduría es concebida como una postura epistemológica ubicada entre la certidumbre y la duda; para ser más precisos, justo en la posición intermedia.

A este respecto, nuestro punto de vista corresponde a la teoría de Meacham y puede caracterizarse como orientado-al-proceso: no es el conocimiento como tal lo que cuenta sino la actitud de las personas hacia el conocimiento y el modo en que aplican este cuerpo de conocimientos.

\section{Sabiduría y moralidad}

Sorprendentemente, el aspecto moral resulta un tópico bastante descuidado en las contribuciones psicológicas sobre sabiduría (Brugman, 1994a; Birren y Schale, 1996). Por el contrario, en muchas nociones filosóficas la sabiduría tiene connotaciones claramente morales. Por ejemplo, Aristóteles en su Retórica (1994) define la phronesis o sabiduría práctica como: "una virtud de la razón, que permite a los hombres llegar a una decisión atinada con respecto a las cosas buenas y malas, que se han mencionado como relacionadas a la felicidad" (p. 93).

Carneades (214-129 A.C., Nueva Academia) afirmaba que la justicia, la sabiduría práctica o prudencia son características de un hombre bueno (Long, 1986). En realidad, es contraintuitivo hablar de alguien que es a la vez sabio e inmoral.

En los primeros años de investigación psicológica sobre la sabiduría, se evidenciaron esfuerzos para realizar un análisis conceptual de ella, valiéndose del examen de las concepciones tradicionales. El intento de Sternberg (1985) reveló como un elemento el "mostrar preocupación por los demás". Holliday y Chandler (1986) encontraron que las personas asocian sabiduría con honestidad, elevada moralidad y confiabilidad, con $5.41,5.00$ y 5.11 puntos, respectivamente, en una escala de 7 puntos (con todo, la asociación más alta fue con "aprende de la experiencia": 6.15 y la más baja con "inteligencia": 3.30 ). 
El estudio de Clayton y Birren (1980) reveló estrechas asociaciones entre sabiduría y empatía, tranquilidad y gentileza, todas las cuales pueden considerarse como rasgos morales. En consecuencia, las concepciones tradicionales sobre la sabiduría contienen elementos morales mas gran parte de las teorías psicológicas sobre sabiduría descuida este aspecto.

Sin embargo, en algunas teorías psicológicas sí se pueden discernir los aspectos morales: por ejemplo, Sowarka (1989b) afirma que la sabiduría implica el uso de nuestros recursos para el bienestar de los demás. Y en los aspectos antes mencionados de la sabiduría (Assmann,1994), uno de ellos tiene una fuerte carga moral: la edificabilidad, que significa que la sabiduría implica conocer lo que es bueno para sí mismo y los demás. De modo que los aspectos morales no están ausentes de la teorización sobre sabiduría pero sí lo están de la principal corriente de investigación sobre el tema.

\section{Sabiduría y satisfacción de vida}

¿La sabiduría contribuye a una "buena vida"? Existen diversas nociones acerca de la relación entre sabiduría y satisfacción de vida. Por ejemplo, Schopenhauer escribió en su Aphorismen zur Lebensweisheit.

Asumo aquí el concepto de sabiduría de vida integramente en el sentido inmanente; es decir, como el arte de llevar la vida lo más agradable y feliz posible, como las instrucciones para poder alcanzar la Eudarmonía; por consiguiente, sería como las instrucciones para una existencia feliz (1995, p. 1781).

En las concepciones tradicionales, sólo se encontró una débil asociación entre sabiduría y felicidad: 4.32 en una escala de 7 puntos, ubicándose en el noveno lugar, comenzando desde abajo, de un total de 79 adjetivos (Holliday y Chandler, 1986).

En la Biblia, se encuentra una relación negativa. En el libro del Eclesiastés, el resultado de la sabiduría es el dolor: 
Y yo deseaba vivamente la sabiduría y el conocimiento. Sentía también que eso era un tormento para el alma. Porque hay mucho dolor en la sabiduría y aquel que aumenta su conocimiento, aumenta su pesar.

A pesar de estas dudas bíblicas inevitables, después de todo, la manzana de Eva no era la manzana del conocimiento, el punto de vista más plausible es hipotetizar una relación positiva entre sabiduría y satisfacción de vida. La destreza en la incertidumbre hace más probable la solución adecuada de los problemas de la vida y junto con ello, una mayor probabilidad de satisfacción de vida.

En la mayoría de las teorías psicogerontológicas, la relación entre satisfacción de vida y sabiduría no es abordada explícitamente. Está, sin embargo, implícitamente presente en diversas teorías. Así, Baltes (1994) concibe la sabiduría como destreza en la pragmática de la vida. Se supone que una persona sabia posee el conocimiento relevante, inclusive de procedimientos, que lo convierte en un experto en manejar la vida. Se espera que tal persona sea capaz de lograr un alto nivel de satisfacción de vida. Y Birren y Fisher ven a la sabiduría como: "la integración de los aspectos afectivo, conativo y cognitivo de las habilidades humanas en respuesta a las tareas y los problemas de la vida" (Sternberg, 1990, p. 326).

Los individuos capaces de lograr tal integración podrían ser también candidatos para una satisfacción de vida elevada.Czikszentmihalyi y Rathunde son más explícitos aún y visualizan a la sabiduría como: "un proceso cognitivo holístico, una virtud o guía precisa para la acción y un estado del ser bueno y deseable" (Sternberg, 1990, p.325).

Como en nuestro punto de vista la sabiduría es una forma de destreza, esto es, destreza en la incertidumbre, uno se puede preguntar para qué se debe ser un experto en tales asuntos. Ciertamente, la destreza en la incertidumbre contribuye a resolver problemas fundamentales de la pragmática de la vida y en este sentido, se debería agregar que contribuye a la satisfacción de vida. Así, en las teorías psicológicas la satisfacción de vida puede 
ser considerada como una consecuencia posible, y hasta plausible, de la sabiduría.

En filosofia, se puede encontrar algo similar. Así, la prudencia (phronesis) es vista como el arte de vivir e implica destreza (Hankinson, 1995). Por ejemplo, Cicerón describe la sabiduría como la "ciencia del vivir" (1994).

En la filosofía helénica, en general, la tranquilidad de la mente o ataraxia era uno de los objetivos básicos de los sistemas filosóficos. Para Pirrón, la tranquilidad de la mente era el producto final necesario de su teoría epistemológica, especialmente la noción de epoché como una condición necesaria (Sixto Empírico, 1994). Cioran (1995) expresa este resultado claramente:

No sé muy bien dónde estoy en relación al escepticismo, aún cuando el mismo está en contra de todo lo que yo he pensado. Lo que es seguro es que para mí ha desempeñado en muchas ocasiones el papel del más eficaz de los tranquilizantes (1995, p. 1781).

Algo relacionado puede encontrarse en Schopenhauer, quien escribió:

Recién a avanzada edad el hombre realmente alcanza el nil admirari de Horacio (no dejarse desconcertar), esto es, el convencimiento inmediato, franco y real de la vanidad de todas las cosas y de la oquedad de todos los esplendores del mundo; las quimeras han desaparecido. El ya no cree que en algún lado, sea en el palacio o en la choza, habita una mayor y especial felicidad y en lo esencial, también disfruta en todas partes, cuando está libre de dolores físicos o espirituales. Lo grande o lo pequeño, lo noble y lo insignificante, según el criterio del mundo, ya no son para él distintos. Esto da al anciano una tranquilidad de ánimo especial con la cual mira hacia abajo sonriente las situaciones del mundo... El rasgo de! carácter fundamental de la vejez es el estar desengañado (1976, p. 251). 
Con todo, uno podría argumentar que justamente lo opuesto es verdad: cuando nada es seguro, cuando no existen opiniones definidas, cuando hay equipotencia en cualesquiera de los argumentos, al individuo le falta alguna forma de anclaje. Y esa falta de anclaje podría dar origen a justamente lo opuesto a la tranquilidad de la mente., como los estoicos sostenían: "El único efecto es ocasionar ese asombro momentáneo, esa irresolución y confusión, que son resultado del escepticismo" (Norton, 1993, p. 93/4).

Desde este punto de vista, se tiene que hacer una distinción entre epoché y aporia o refutación. El escepticismo aporético apunta a refutar las posiciones dogmáticas; y en este sentido, se le puede considerar como un dogmatismo negativo y puede llevar a un estado de frustración epistémica como consecuencia de la refutación de cada uno de los intentos de apoyar una pretensión de conocimiento (Woodruff, 1988).

El falibismo o probabilismo de Carneades es tal vez el compromiso correcto. Su teoría puede ser considerada como una reconciliación de la desesperación de los aporéticos y la tranquilidad mental de los pirronistas estrictos. Saber que nada se puede conocer con seguridad, saber que todo es vano; sin embargo, actuar adecuadamente a pesar de este desalentador punto de vista escéptico.

\section{Dimensionalidad}

Hasta aquí, la sabiduría ha sido abordada como un concepto bipolar unidimensional: sabiduría, por un lado; estupidez, vicio y tontería, por el otro. Con todo, sigue siendo una posibilidad que la sabiduría sea multidimensional así como la inteligencia a veces se supone que es. DittmannKohli (1984) hace una distinción entre tres tipos de sabiduría: filosófica, práctica o relacionada a la persona e interpersonal. Esta clasificación es en parte semejante a la tríada platónica, conformada por sophia o la búsqueda de la verdad; phronesis o sabiduría práctica; y episteme o conocer la naturaleza de las cosas y los principios que gobiernan la conducta (Sternberg, 1990). Inclusive se parece a la distinción kantiana entre "reinen", "praktischen" y "kritischen Vernunfi". Algo específico a la clasificación de 
Dittmann-Kohli es la variante relacionada-a-la-persona. Assmann (1990; 1994) sostiene que la sabiduría es un término valorativo, inmerso en un contexto cultural y en consecuencia, altamente polimorfo. La autora hace una distinción entre cuatro formas de sabiduría: paternal, mágica, escéptica y del tipo estadista, las cuales corresponden, respectivamente, a las sabidurías de Polonio, Próspero, Jacques y Salomón; los tres primeros nombres se derivan de las obras de Shakespeare (ver cuadro 2).

\section{Cuadro 2}

Cuatro tipos de sabios (Assmann, 1990; 1994)

\begin{tabular}{|l|l|}
\hline Polonio & $\begin{array}{l}\text { Sabiduría paternal: experiencia, advertencia y consejo; conoci- } \\
\text { miento práctico; sabiduría proverbial, tradicional, relacionada } \\
\text { a la phronesis o sabiduría práctica (Long, 1986). }\end{array}$ \\
\hline Próspero & $\begin{array}{l}\text { Sabiduría mágica: magia; alquimia; misterio, basados en el } \\
\text { conocimiento esotérico del mundo cósmico. }\end{array}$ \\
\hline Jacques & $\begin{array}{l}\text { Sabiduría escéptica: sabiduría no normativa, caracterizada por } \\
\text { la distancia, la melancolía, la ironía y la duda; cambio de una } \\
\text { orientación de solución de problemas a una búsqueda de pro- } \\
\text { blemas; marco de orientación del universo no-lógico, contra- } \\
\text { dictorio y no permanente; desafía la misma idea de sabiduría } \\
\text { como virtud. }\end{array}$ \\
\hline Salomón & $\begin{array}{l}\text { Sabiduría judicial y política: el juicio, la decisión, la predicción; } \\
\text { característica sobresaliente es la agudeza de un juicio no sesgado, } \\
\text { basado en el conocimiento del mundo social. }\end{array}$ \\
\hline
\end{tabular}

Especialmente uno de los tipos de sabiduría según Assmann, la forma escéptica de Jacques, está relacionado a la variante de escepticismo encontrada en la filosofía helénica, no la pirronista sino la falibilística. Assmann describe la sabiduría escéptica de Jacques como una forma de sabiduría en la que la distancia es la característica más prominente. La sabiduría escéptica de Jacques se caracteriza por la distancia, la melancolía, la ironía y la duda y se puede subdividir en pesimista y optimista. Un ejemplo de 
la variante pesimista puede encontrarse en los Ensayos de Montaigne (1991), en donde el autor elabora el concepto de "providencia inmanente". En psicología, esto es comparable con la concepción de pensamiento . postformal de Arlin (1975), que puede describirse como de descubrimiento del problema; y con el pensamiento dialéctico de Riegel inserto en su teoría de desarrollo cognitivo (1973). El pensamiento dialéctico está orientado hacia la "naturaleza ilógica, contradictoria e inestable del universo" (Assmann, 1994, p. 210). Ambas teorías remarcan la importancia de un tipo de actitud anárquica hacia el conocimiento: cuestionar lo que en apariencia es auto-evidente, no dar nada por sentado. Así, esta sabiduría de Jacques es semejante a nuestro punto de vista de sabiduría "contemporánea", caracterizada por el equilibrio epistémico entre la certidumbre y la duda. Jacques reconoce la posibilidad de que lo que ahora parece verdad pueda, tarde o temprano, resultar falso.

Luego de estas reflexiones acerca de la naturaleza de la sabiduría, abordaremos ahora un problema aún más difícil, el de los cambios en la sabiduría a lo largo de la vida.

\section{Los cambios en el curso de la vida}

Las diferencias entre grupos de edad no existen en el vacío, ni tampoco los cambios dentro de los individuos respecto de ciertas dimensiones psicológicas. La edad es generalmente un predictor importante de tales diferencias, cambios y/o procesos del desarrollo pero existen otras fuentes de varianza, como la cultura y la historia, que podrían ser importantes, especialmente en el caso de la sabiduría. Las mismas podrían influir sobre la naturaleza de la sabiduría así como sobre los gradientes del cambio. Dittman-Kohli (1984), por ejemplo, sugiere que aún cuando la complejidad y número de problemas en el campo de las relaciones interpersonales no aumentan mucho comparados con los del campo tecnológico, sin embargo, las demandas en el campo interpersonal son crecientes en la sociedad contemporánea debido al aumento en la complejidad de las relaciones humanas. Y optimistamente añade a ello, el creciente conocimiento sobre este campo por el aporte de las ciencias sociales. De lo 
anterior, la autora infiere que en la sociedad los conocimientos aumentan más rápidamente que la habilidad del individuo para adquirir tales conocimientos por cuenta propia. Con todo, esto sigue siendo debatible. En realidad, en las sociedades occidentales hay más elecciones que hacer en el campo interpersonal pero es apresurado concluir que por tal razón la complejidad aumenta. La única conclusión que puede extraerse con seguridad es que la naturaleza de los problemas en el campo interpersonal cambia con el tiempo. Además, las ciencias sociales han acrecentado nuestro conocimiento sobre la conducta humana mas uno puede cuestionar su disponibilidad, para no hablar de su validez e inclusive, la adquisición de ese conocimiento podría aumentar la dificultad de las elecciones interpersonales. El saber o conocer más no implica actuar con mayor facilidad.

Con respecto a la cultura, Assmann sostiene que la sabiduría florece en sociedades que no son ni demasiado estrictas ni demasiado anárquicas (1994). Y Nietzsche en su tiempo argumentaba que la asociación edadsabiduría estaba desapareciendo. La sabiduría tradicional era para el enfermizo y el desdentado (ver también Marquart, 1986; y Cioran, 1995). Así, existen amplias razones para considerar cuidadosamente las diferencias culturales y los cambios históricos y desde este punto de vista, es oportuna una digresión histórico-cultural. A través de los años, la sabiduría es vista sucesivamente como se presenta en el Cuadro 3.

Esta revisión histórica es tentativa y sólo sirve al propósito de mostrar los cambios en la naturaleza y coincidentemente, la ontogénesis y los determinantes de la sabiduría. Con relación al lugar de la sabiduría en las sociedades occidentales contemporáneas, Marquart sostiene que existe una tendencia en el sentido de que el envejecimiento sea concebido como coincidente con la pérdida de sabiduría (1986). A esto el autor lo denomina como un proceso de desfamiliarización con el mundo, el cual implica una devaluación dramática de la experiencia. Así, varios teóricos afirman más bien tristemente que la experiencia ha perdido su valor en el siglo $\mathrm{XX}$ (ver también Assmann, 1994). No habría acumulación de conocimientos simplemente porque tal acumulación no sería muy adaptativa en sociedades 
La sabiduría

Cuadro 3

Cambios históricos en la naturaleza, fuente e importancia atribuida de la sabiduria (seguin Assmann, 1994; Sternberg, 1990)

\begin{tabular}{|l|l|}
\hline Una virtud & $\begin{array}{l}\text { Por ejemplo, los proverbios de Ptah } \\
\text { Hotep en Egipto, hace casi 4500 años. }\end{array}$ \\
\hline Un don divino & $\begin{array}{l}\text { Los griegos; por ejemplo, Aristóteles; } \\
\text { la Biblia. }\end{array}$ \\
\hline $\begin{array}{l}\text { Cristo, la cima del aprendizaje, } \\
\text { la fé simple }\end{array}$ & La Edad Media \\
\hline Contemplación & Renacimiento \\
\hline Ocaso & Era Científica \\
\hline Regreso & Postmodernismo; epistemología \\
\hline
\end{tabular}

industrialmente muy desarrolladas. $\mathrm{Y}$ como la sabiduría está asociada fuertemente con la experiencia, debe en consecuencia desaparecer gradual y silenciosamente porque ha dejado de tener un valor adaptativo. No obstante, este modo de ver es debatible desde que su punto de partida es una conceptualización de la naturaleza de la sabiduría dirigida hacia el contenido; mientras que un enfoque más dirigido hacia el proceso parece más prometedor. Debe destacarse que similares puntos de vista dirigidos hacia el contenido son expresados por Baltes y su grupo de Berlín (Baltes, 1994; Baltes, Staudinger, Maercker \& Smith, 1995; Sowarka, 1989a; Staudinger, 1989; Staudinger, 1990), quienes operacionalizan la sabiduría en términos de acumulación de conocimientos. Como se mencionó anteriormente, también existen enfoques dirigidos hacia el proceso [ver, por ejemplo, Kitchener (1983); Meacham (1983; 1990)], y los neopiagetanos (Labouvie-Vief, 1992)).

Como en nuestra perspectiva, la sabiduría no es un asunto de la cantidad de conocimientos sobre la pragmática de la vida per se sino, más bien, de la calidad con que se lidia con ella, no se dan esos signos amenazadores del deterioro de la sabiduría con el tiempo. Por el contrario, 
debido a la velocidad con que circula el conocimiento y a la velocidad con que el conocimiento se vuelve obsoleto, tal actitud hacia el conocimiento es a todas luces útil. Ultimamente está ocurriendo un cambio con relación a la naturaleza de la sabiduría; en términos de la división tetrapartita de Assmann (1990; 1994), habría un cambio de la sabiduría paternal de Polonio y la sabiduría mágica de Próspero a la variante escéptica de Jacques.

Luego de esta digresión histórico-cultural, revisaremos los aspectos ontogenéticos de la sabiduría. Como se indicó anteriormente, tanto las teorías científicas como las nociones psicológicas tradicionales asumen por lo general una relación positiva entre edad y sabiduría. Una clara ilustración de esta noción de sentido común puede encontrarse en la siguiente cita: "No hay sabiduría en los primeros años. El sabio tiene los hombros encorvados" (Gent, 1966, p. 77).

Sin embargo, existe una peculiar paradoja en aquellas nociones. Por un lado, el envejecimiento cognitivo es visto como un proceso de deterioro, tanto en la psicología científica como en la tradicional. El decaimiento de diversas funciones cognitivas está bien documentado aún cuando la interpretación de los hallazgos todavía es equívoca (Brugman \& Heymans, 1994; Salthouse, 1991). De otro lado, el envejecimiento está asociado al crecimiento mental en general y al crecimiento de la sabiduría en particular (Brugman, 1994; Sternberg, 1990). Las nociones de los legos acerca de la sabiduría y la edad implican una relación positiva, donde el envejecimiento está asociado con el incremento de la experiencia y la experiencia está ligada positivamente a la sabiduría. Lo mismo ocurre en la ciencia, la mayoría de las teorías gerontológicas acerca de la sabiduría, las teorías neo-piagetanas acerca del pensamiento postformal, que es un campo relacionado a la sabiduría, y las teorías sobre pensamiento reflexivo; apuntan en dirección del crecimiento; aunque cabe señalar que no existe todavía evidencia empírica sólida que apoye estas posiciones teóricas (Baltes \& Smith, 1990; Denney, 1995; Kitchener, 1983; Labouvie-Vief, 1992).

Existen diversos modos de reconciliar estas nociones aparentemente contradictorias. Primero, el crecimiento y el deterioro podrían pertenecer 
a diferentes "campos" del funcionamiento cognitivo. Implícita a dicha presunción está la necesidad de que ambos campos no se afecten entre sí y/o que el funcionamiento en un campo se apoye en recursos diferentes a los del otro. Se han sugerido algunas dicotomías para diferenciar los campos del funcionamiento cognitivo. Labouvie-Vief (1990), por ejemplo, establece una distinción entre el campo de la lógica y el de lo "psico" lógico. Baltes contrasta la mecánica y la pragmática de la inteligencia (Baltes, 1987) y el bien conocido enfoque de Cattell-Horn sobre inteligencia diferencia entre la forma fluida y la cristalizada. Todas estas diferencias pueden reducirse a las diferencias en la contribución de la experiencia en el funcionamiento intelectual. En consecuencia, lo "psicológico", la pragmática de la inteligencia y la inteligencia cristalizada se supone que están firmemente enclavados en la experiencia. Esto en contraste con la lógica, la mecánica de la inteligencia y la inteligencia fluida las cuales no están ligadas a contenidos y se asocian fuertemente a la velocidad, la capacidad de la memoria operativa y la energía mental, que son los llamados recursos fundamentales de procesamiento (Salthouse, 1990). Esta presunción concuerda en mucho con los principios de Baltes sobre el desarrollo en el curso de la vida. Según estos principios de multidimensionalidad y multidireccionalidad (Baltes, 1987), se espera que en el desarrollo humano ocurra justamente un crecimiento y un declive simultáneos, a lo largo de la vida.

Una segunda solución puede encontrarse en uno de los principales supuestos del paradigma gerodinámico, en el que el envejecimiento es definido como "el proceso de incremento de la entropía con la edad de los individuos, de la cual emergen el desorden y el orden" (Schroots, 1995, p. 57). Aplicado esto al campo cognitivo el deterioro cognitivo puede conducir no sólo a niveles funcionales inferiores sino también superiores. Assmann (1994), por ejemplo, sugiere que la sabiduría es un recurso precioso para compensar el declive de las capacidades físicas.

La solución más atrevida es propuesta por Pascual-Leone (1984), una solución que podría considerarse como una versión más fuerte que la anterior. El sostenía que la dinámica de la progresión en la cognición adulta 
está impulsada exactamente por el deterioro que da pie a nuevas reorganizaciones funcionales. Si bien esto es simplemente una hipótesis, es posible que las crecientes limitaciones ocasionadas por el deterioro de algunos subdominios intelectuales conduzcan a un nuevo funcionamiento óptimo, por ejemplo, forzando a que el individuo utilice recursos aún intocados (Heymans \& Brugman, 1995). Se pueden encontrar algunas nociones evolutivas similares en el trabajo de Assmann, quien asume que la sabiduría escéptica puede ser vista como resultado del relativismo maduro, más específicamente como una alternancia de la sapiencia y la fortaleza. Cuando la fortaleza disminuye, tiene que ser reemplazada por la sabiduría. En este sentido, lo anterior puede ser considerado como una instancia del supuesto gerodinámico que señala que el aumento de la entropía puede llevar a un nivel cognitivo superior (Schroots, 1995). Schopenhauer, por ejemplo, escribió en su Aphorismen zur Lebensweisheit.

Es cierto que en la edad avanzada también disminuyen las facultades mentales: pero donde hubo bastante quedará aún suficiente para la lucha contra el aburrimiento. Es así que, como se mostró anteriormente, gracias a la experiencia, el conocimiento, la práctica y la reflexión, aumenta la correcta comprensión, el juicio se agudiza y el contexto se aclara; se gana en todas las cosas; en una perspectiva más y más unificadora del todo. En consecuencia, la continua autoformación interna de todos sus elementos, las nuevas combinaciones de los conocimientos acumulados y el eventual enriquecimiento de los mismos, ocupan, satisfacen y recompensan el espíritu. Por medio de todo ello se compensa en cierto grado la mencionada disminución (1851/1976, p. 252).

Así, el declive intelectual y el crecimiento de la sabiduría no se excluyen necesariamente entre sí. Por el contrario, el declive en un campo podría ser el precio del crecimiento en el otro. En realidad se trata de la "ley sublime" de la vida, tal como la expresó Emerson (1990), la cual denota el equilibrio compensatorio entre ganar y perder. $Y$ esto nuevamente ha de encontrarse en el enfoque de ganancias y pérdidas propuesto por Baltes (1987) para explicar el desarrollo a lo largo de la vida. En consecuencia, 
lo que todavía requiere explicación no es la coexistencia del crecimiento y el declive cognitivos sino la discrepancia entre las concepciones tradicionales y las teorías gerontológicas respecto de la relación entre edad y sabiduría, por un lado, y los datos empíricos, por el otro. Se espera una relación positiva aunque hasta el momento no ha sido encontrada. El Cuadro 4 muestra parte de la escasa evidencia empírica sobre esta relación.

Como puede verse, en tres estudios no se halló relación alguna. En el estudio conducido por Kitchener et al. (1989) se encontró una relación positiva; sin embargo, el rango de edad estudiado se restringió a adolescentes. Los dos estudios sobre concepciones tradicionales revelaron una relación positiva.

Teóricamente, existen diversos argumentos para la hipótesis de que la sabiduría aumenta con la edad. En primer lugar, como la sabiduría se asocia fuertemente a la experiencia, tanto en las concepciones tradicionales como en las teorías psicológicas, se podría esperar un aumento de la sabiduría con la edad simplemente porque la edad y la experiencia correlacionan positivamente. Volveremos más tarde a abordar el rol de la experiencia en la génesis de la sabiduría.

De otro lado, Mergler y Goldstein asumen un punto de vista evolutivo: consideran que los cambios fisiológicos y cognitivos que ocurren a edad avanzada constituyen una fase adaptativa del desarrollo por derecho propio. Un enfoque más dirigido hacia el contenido, dentro de un marco evolutivo, ha de encontrarse en el trabajo de Csikszentmihalyi y Rathunde (Sternberg, 1990). Los autores hacen uso del constructo "meme", que es el equivalente cultural de gene y que se supone afecta la sobrevivencia del fenotipo humano. El "meme" de la sabiduría contiene un núcleo de significado que provee instrucciones para el pensamiento y la acción. De modo que en su teoría, la evolución prosigue no sólo por las instrucciones bioquímicas sino, también, por aprendizaje cultural. Sin embargo, no está claro lo que se quiere decir con "núcleo de significado". Obviamente, la sabiduría no implica instrucciones fijas de cómo vivir. 


\section{Cuadro 4}

Revisión de la relación entre sabiduria y edad en la investigación

\begin{tabular}{|c|c|c|c|}
\hline Autor(es) & $\begin{array}{l}\text { Operacionalización } \\
\text { de la sabiduria. }\end{array}$ & $\begin{array}{l}\text { Grupos } \\
\text { de edad. }\end{array}$ & $\begin{array}{l}\text { Relación } \\
\text { Edad-Sabidurfa. }\end{array}$ \\
\hline $\begin{array}{l}\text { Baltes \& } \\
\text { Smith } \\
(1990)\end{array}$ & $\begin{array}{l}\text { destreza en la pragmá- } \\
\text { tica de los problemas } \\
\text { fundamentales de la } \\
\text { vida: entrevista, uso de } \\
\text { viñetas hipotéticas. }\end{array}$ & $\begin{array}{l}\text { jóvenes adultos; su- } \\
\text { jetos de mediana y } \\
\text { avanzada edades } \\
\text { (alto nivel educa- } \\
\text { cional) }\end{array}$ & no hay relación \\
\hline $\begin{array}{l}\text { Baltes, } \\
\text { Staudiinger, } \\
\text { Maercker } \\
\text { \& Smith } \\
\text { (1995) }\end{array}$ & ibid. & $\begin{array}{l}\text { jóvenes adultos; su- } \\
\text { jetos de mediana y } \\
\text { avanzada edades } \\
\text { (candidatos a } \\
\text { sabios) }\end{array}$ & no hay relación ( $r=.05 \mathrm{~ns})$ \\
\hline $\begin{array}{l}\text { Brugman } \\
\text { (1995) }\end{array}$ & cognición epistémica & $\begin{array}{l}\text { amplio rango de } \\
\text { edad: } 20-70\end{array}$ & no hay relación $(r=.02 n s)$ \\
\hline $\begin{array}{l}\text { Kitchener, } \\
\text { King, } \\
\text { Wood \& } \\
\text { Davidson } \\
(1989)\end{array}$ & $\begin{array}{l}\text { escala de juicio } \\
\text { reflexivo }\end{array}$ & $\begin{array}{l}\text { pequeño rango } \\
\text { de edad: sólo } \\
\text { con sujetos jóvenes } \\
\text { (adolescentes) }\end{array}$ & relación positiva \\
\hline $\begin{array}{l}\text { Sternberg } \\
\text { (1985) }\end{array}$ & $\begin{array}{l}\text { concepciones } \\
\text { tradicionales }\end{array}$ & $\begin{array}{l}\text { profesores, } \\
\text { estudiantes y } \\
\text { adultos }\end{array}$ & $\begin{array}{l}\text { polaridad positiva de } 3^{\text {ra }} \\
\text { dimensión: para mayores, } \\
\text { maduros o de larga expe- } \\
\text { riencia }\end{array}$ \\
\hline $\begin{array}{l}\text { Holliday \& } \\
\text { Chandler } \\
\text { (1985) }\end{array}$ & $\begin{array}{l}\text { Concepciones tradicio- } \\
\text { nales }\end{array}$ & $\begin{array}{l}\text { jóvenes adultos; } \\
\text { adultos de edad } \\
\text { mediana; y ciuda- } \\
\text { danos mayores. }\end{array}$ & $\begin{array}{l}\text { para los mayores: valor de } \\
\text { calificaciónde } 4.50 \text { en una } \\
\text { escala de } 7 \text { puntos, n } n^{\circ} 65 \\
\text { en unalistade } 80 \text { adjetivos } \\
\text { para los maduros: valor de } \\
\text { calificación de } 5.95, n^{\circ} 5 \\
\text { en la misma lista. }\end{array}$ \\
\hline
\end{tabular}


En tercer lugar, existe el argumento, utilizado por los neopiagetanos como Labouvie-Vief, Kitchener, Cramer y otros (ver, por ejemplo, Commons et al. 1990), de que es poco plausible negar cualquier desarrollo cognitivo posterior en la adultez. La hipótesis del desarrollo máximo en la adolescencia, sostenida por Piaget, resulta rechazada. Por consiguiente, se hipotetiza un quinto estadio del desarrollo cognitivo; el estadio postformal. Este estadio postformal se caracteriza justamente por aquellas características que se encuentran en las descripciones de sabiduría.

Así que deben haber fuertes razones que expliquen la falta de evidencia empírica. Una explicación puede encontrarse en la sugerencia mencionada antes por Dittmann-Kohli (1984), las diferencias grupales debidas al rápido crecimiento del cuerpo de conocimientos sobre las relaciones interpersonales favorecen a los grupos más jóvenes. $Y$, hasta ahora, no han habido estudios longitudinales o secuenciales. Entonces, la confusión de la varianza por edad y por grupo es una explicación posible.

Además, el modo en que la sabiduría es conceptualizada y operacionalizada resulta debatible. Primero, el sesgo de contenido. La sabiduría, hasta ahora, ha sido enfocada como una variable de producto, como el conocimiento de hechos y de procedimientos en el campo de la pragmática de la vida. Segundo, la forma en que se evalúa la sabiduría es cuestionable, el procedimiento estándar en la investigación del Instituto Max Planck [ver, por ejemplo, Baltes \& Smith (1990), Baltes, Staudinger, Maercker \& Smith (1995); Staudinger (1990), Sowarka (1989a) ] consiste en pedir a los sujetos que reaccionen a viñetas en las que se describe un problema existencial; por ejemplo, un amigo llama por teléfono y nos dice que va a suicidarse, ¿cómo reacciona usted? Las respuestas se anotan y puntúan en base a cinco criterios de sabiduría: el conocimiento de hechos y el conocimiento de procedimientos como componentes esenciales y centros de cualquier conocimiento experto, y tres metacriterios, el manejo de la incertidumbre, el contextualismo y el relativismo. Todos los criterios son evaluados en una escala de 7 puntos por personas entrenadas. Luego se calcula la media, obteniéndose un puntaje de sabiduría. Diversos argumentos se pueden contraponer a este procedimiento. Primero que nada, los 
criterios no están pesados aún cuando los componentes del conocimiento son considerados como esenciales. Sólo hay una suma de los puntajes obtenidos en los cinco criterios. Segundo, los sujetos tienen que responder a problemas hipotéticos. La investigación de Blanchard-Field y Camp (1995) ofrece evidencia de que lo emocional es un aspecto importante del problema. Tercero, el tiempo utilizado para la evaluación de las respuestas es restringido. Sin duda, éste es suficientemente largo pero difiere de la "vida real". Al ser confrontado con un problema existencial, el individuo normalmente tiene que meditar en ello. Se requiere cuando menos algún tiempo de incubación aunque a veces es necesaria la acción rápida. Así se puede cuestionar la validez ecológica del procedimiento. Un procedimiento más promisorio parece ser el uso de material autobiográfico (Brugman, 1995).

Resumiendo: aunque teóricamente es plausible una relación positiva entre edad y sabiduría, la evidencia empírica sugiere otra cosa. Y además de argumentos metodológicos, existen argumentos teóricos que apoyan los hallazgos investigativos en el sentido de ausencia de relación.

Partiendo de nuestra descripción funcional de sabiduría como una forma de escepticismo moderado o falibilismo, se supone que ella cambia de un modo no evolutivo a lo largo de la vida (Brugman, 1994a; 1994b; Meachan, 1983; 1990). Concebida como una postura epistemológica, se hipotetiza que los cambios ocurren como una función de la confrontación y el afrontamiento de los eventos de vida y de la acumulación de conocimientos. Tal confrontación conducirá a un desequilibrio epistemológico y resultará en un nuevo nivel epistemológico.

Así que podría haber cambio mas no desarrollo. Sin embargo, existe un aspecto, no esencial empero, que puede considerarse como evolutivo en esencia; la calidad de la sabiduría, si bien el término "calidad" no es el apropiado. Un mejor término es la profundidad de la sabiduría (Assmann, 1994). Como la sabiduría denota una actitud hacia el conocimiento y una forma de manejario, es obvio que el producto sea función de la cantidad y calidad de lo que se conoce. De modo que la acumulación de conoci- 
mientos y el desarrollo cognitivo determinan la calidad del producto. Es este aspecto de la sabiduría que se supone cambia de una forma evolutiva. $\mathrm{Y}$ es justamente en este punto que las concepciones tradicionales y la mayoría de las teorías sobre sabiduría convergen en el considerable peso que colocan sobre el componente del conocimiento, el cual desde nuestra perspectiva sólo es secundario. Además, las variables cognitivas de la personalidad, como la apertura a la experiencia, predeterminan al individuo para una postura epistémica específica (ver figura 2).

Para ilustrar el punto de vista de que la sabiduría no necesita tener una columna vertebral encorvada sino que también puede encontrarse en niños, sólo podemos ofrecer alguna evidencia casuística. La investigación con respecto a la sabiduría en niños es inexistente. Con todo, alguna investigación está por aparecer.

En los protocolos de jóvenes adolescentes que hablan sobre problemas filosóficos relacionados a la verdad se logra identificar el elemento nuclear de la sabiduría, el pensamiento probabilístico o falibilístico:

C: Quizá la verdad es algo en lo que tú crees que es posible...pero cuando realmente crees en algo, entonces esa es la verdad para ti. Quiero decir, cuando uno es pequeño y crees en Papá Noel, esa creencia es tu verdad. $Y$ todos nosotros creemos que el universo es infinito y entonces crees que eso es verdad. Quizá no es infinito, quizá es una pequeña carga negativa dentro de otro sistema mayor, de un orden diferente.

K: Quizá no existen leyes físicas en absoluto; quizá las construimos porque es fácil.

K: Sí pero ¿cómo sabemos que algo no es verdad si no sabemos nada con seguridad? (Rondhuis, datos en bruto sin publicar)

Rondhuis (1994) describe las discusiones filosóficas o los ejercicios en pensamiento indeciso, con niños del último grado de la escuela primaria; esto es, niños de 12 años de edad. En medio de una discusión, uno de los niños gritó repentinamente: 
Quizá toda la vida es sólo nada, la tierra, el universo. Quizá todo es un sueño, que nunca termina (p. 76).

Las siguientes citas de la misma discusión ilustran un alto nivel de pensamiento epistémico también:

¿Quién decide qué existe? (p. 84).

En realidad todo es falso! Sólo hemos dado nombres a las cosas. Pero ¿quién sabe que esto en lo que estoy sentado es una silla? No es una silla en absoluto. Para los simios, es una cosa para trepar, para los ratones es quizá una casa. Una silla no existe en absoluto. Todo es falso! (p. 14).

O la del niño de 5 años de edad quien, ante la pregunta de mencionar los tres eventos más importantes de su vida, respondió:

Nací, vivo y moriré" (Povalinova, datos en bruto sin publicar).

Aunque estas citas son sólo ilustraciones, indican que la sabiduría es posible tan tempranamente como en los años preescolares. Y si bien su "profundidad" podría ser diferente a la de la sabiduría adulta, de todas maneras se parecen mucho. La investigación futura tiene que encarar este problema.

\section{Determinantes del cambio}

Poco se sabe acerca de los determinantes específicos de las diferencias en sabiduría entre los individuos y entre grupos de edad; y de los cambios intraindividuales en sabiduría a lo largo de la vida. Sin embargo, existen algunos candidatos a explicar estas diferencias y cambios; la experiencia asociada con el encuentro/afrontamiento de los eventos de vida, la acumulación de conocimientos, factores de personalidad como apertura hacia la experiencia y tolerancia a la ambiguedad, y el desarrollo cognitivo. 


\section{a. Eventos de vida $y$ experiencia}

La mayoría de los autores atribuye a la experiencia y a los eventos de vida un rol importante en la ontogénesis de la sabiduría. Baltes y Smith (1990) mencionan factores específicos de destreza, como la práctica con problemas de la vida y la tutoría organizada. Assmann (1994) sostiene también que los determinantes de los eventos de vida son cruciales para la ontogénesis de la sabiduría: "los retos biográficos específicos, además de los genéricos, que crean el horizonte específico a la edad de posibilidades, tareas y retos" (p. 215).

Meacham (1983; 1990) también enfatiza el rol de los eventos de vida aunque más como determinantes de cambio que de desarrollo. Los eventos de vida pueden forzar a un individuo a adherirse a certezas, por ejemplo, a aquellas encontradas en la religión; la duda absoluta, posiblemente conduciéndolo a la inercia.

Un problema específico tiene que ver con la relación entre eventos de vida y experiencia: la experiencia puede derivarse de la confrontación y el afrontamiento de los eventos de vida aunque no necesariamente. La pregunta a ser respondida es: ¿por qué algunas personas se benefician de ella y otras no? La experiencia es sólo una condición necesaria. Ese hacer uso de la experiencia es descrito de modo fascinante por Nietzsche (1972) como "unlogischen Verallgemeinerung" o generalización ilógica.

Otra respuesta posible a la pregunta de cómo es que la gente logra beneficiarse de la experiencia, podría encontrarse en una actitud específica hacia el conocimiento:

Una intuición más profunda del orden parece ser característica de la sabiduría. Este orden implícito para el cual propongo el término de providencia inmanente no es en absoluto obvio; es difícil discernirlo y requiere atención y percatamiento continuos. Atención, distancia, confianza y escepticismo se mezclan en esta actitud hacia el mundo (Assmann, 1994, pp. 194-195). 
Dittman-Kohli (1984), al discutir la sabiduría en un contexto histórico, enfatiza el rol de los esfuerzos personales y de las condiciones ambientales favorables en la adquisición de sabiduría: la autora no considera a la sabiduría como un rasgo innato ni tampoco supone que ella simplemente se desarrolla. Y Baltes también investiga las condiciones favorables. En una investigación reciente (Baltes et al., 1995), él compara sabios nominados como tales, jóvenes adultos y ancianos normales con terapeutas mayores, suponiéndose que estos últimos son expertos en pragmática de vida.

Si bien en muchas teorías filosóficas y psicológicas, incluyendo las tradicionales, y en los relatos históricos, se enfatiza la importancia de la experiencia en la génesis de la sabiduría, hay algunas excepciones. Así, Aristóteles en su Retórica (1994) enfatiza el impacto negativo de la experiencia sobre casi todo rasgo humano:

El hombre mayor y aquellos que han dejado atrás la flor de la vida tienen en la mayoría de los casos caracteres opuestos a aquellos de su juventud. Porque como han vivido muchos años y muy a menudo han sido engañados por los demás o ellos mismos han cometido muchos errores y puesto que la mayoría de las cosas resultan malas, ellos no son positivos acerca de nada... Son maliciosos porque la malicia consiste en considerar el peor lado de todo. Además, siempre están suspicaces debido a la desconfianza y desconfiados debido a la experiencia (p. 251).

Y el gran escritor holandés del siglo XIX Multatuli, al describir a uno de sus protagonistas, Woutertje Pieterse, escribió:

Es realmente una pena que él "estudie" o en cualquier caso, que sea un... estudiante. Y es una pena también que posteriormente él -más perverso que ahora- pierda todavía más sabiduría, al escuchar a esa impertinente amante de la locura: la experiencia (Multatuli; idea 1007, volumen 6, p. 283). 
Estas advertencias implícitas encajan limpiamente con nuestra noción acerca del rol de la experiencia en la sabiduría: la experiencia como tal no tiene valor predictivo respecto de la sabiduría. El lidiar toda la existencia con los eventos de la vida puede hacer que un individuo se desvíe de la sabiduría y se dirija a cualquiera de estas dos direcciones, hacia la rigidez o hacia la desesperación (Brugman, 1994a; 1994b; Meacham, 1990).

\section{b. Acumulación de conocimientos}

Saber más y más puede influir en la postura epistémica de un individuo de dos maneras opuestas: por un lado, el individuo puede volverse consciente de que no sabe nada. Ocurre como en la metáfora de la montaña: escalar la montaña del conocimiento implica ver todo el conocimiento que todavía no se conoce. Por otro lado, el individuo puede obtener la impresión de que a medida que su conocimiento crece, la parte que queda por conocerse se encoge. Las diferentes posturas son descritas con finura por Quevedo y Schlegel:

Este es el modo en el que el muy erudito Francisco Sánchez, médico y filósofo, nos narra en su libro, que se titula Nihil Scitur. No sabemos nada. Existen personas en el mundo que no saben nada y estudian para saber. Tienen buenas intenciones pero se cansan en vano porque al final su estudio sólo sirve al propósito de descubrir que no saben toda la verdad. También existen personas que no saben nada y no estudian porque creen que lo saben todo. Hay muchas de ellas y son incorregibles. Se les debe envidiar por su holgazanería y satisfacción pero se les debe compadecer por la pobreza de sus juicios. Todavía existen otras personas que no saben nada y que dicen que no saben nada pero en realidad piensan que saben algo aunque no saben nada y a ellas se les debe castigar por su hipocresía para creerse su confesión. Otras más, ellas son las más tercas y yo soy una de ellas, no saben nada, no quieren saber nada, no quieren creer que en general algo pueda conocerse y dicen que nadie sabe nada, que todos dicen lo mismo de ellas y que nadie está mintiendo (Quevedo, 1992, p. 99-100). 
"Mientras más sepa uno, más tiene que aprender. Con el saber se incrementa el no saber en igual grado, o más bien el saber del no saber" (Schlegel, 1978, p. 110).

Así, la acumulación de conocimientos puede alterar la posición epistémica propia de una manera u otra; puede llevar a cambios en la proporción percibida del conocimiento adquirido respecto de lo que es posible conocer (Meacham, 1983).

\section{c. Personalidad}

Es obvio que la personalidad es un predeterminante importante de la sabiduría. Sin embargo, saber esto no responde a la pregunta sobre la naturaleza de la relación entre sabiduría y personalidad. Escasean tanto investigaciones como nociones teóricas tentativas sobre el particular. La única excepción es Erikson. Su teoría acerca del desarrollo de la personalidad nos brinda algunas pistas. La sabiduría es, desde su perspectiva, el producto de la solución de la última crisis vital; esto es, la crisis de la integridad del ego versus la desesperación.

Segundo, existen posiblemente elementos provechosos en el enfoque de personalidad de los Cinco Grandes: especialmente el más bien oscuro quinto factor podría ser un posible determinante para la ontogénesis de la sabiduría. El quinto de los cinco factores se describe algunas veces como "apertura hacia la experiencia" (McCrea \& Costa, 1987). Tal actitud podría considerarse como una precondición importante para la existencia de la sabiduría.

\section{Desarrollo cognitivo}

El último determinante a discutirse brevemente es el desarrollo cognitivo. Se supone que el desarrollo cognitivo influye sobre la calidad o profundidad de la sabiduría porque determina el material sobre el cual puede actuar la actitud epistémica. Las nociones de Riegel acerca de la posibilidad del desarrollo de una forma dialéctica en cada estadio cognitivo sugieren que el desarrollo cognitivo como tal no se relaciona con la sabiduría (Meachem, 
1990; Brugman, 1994a). Baltes $\&$ Smith (1990) proponen un modelo de desarrollo y mencionan a la educación, la mecánica cognitiva y el aprendizaje cultural como posibles factores para la ontogénesis del conocimiento.

\section{Modelo Heurístico y algunas desiderata}

Concluiremos esta contribución ofreciendo un modelo heurístico de la sabiduría (figura 3) y de los cambios que experimenta a lo largo de la vida; así como algunas desiderata respecto de pasos adicionales que deben considerarse en el estudio de la sabiduría.

Figura 3

Modelo estructural de la sabiduria escéptica

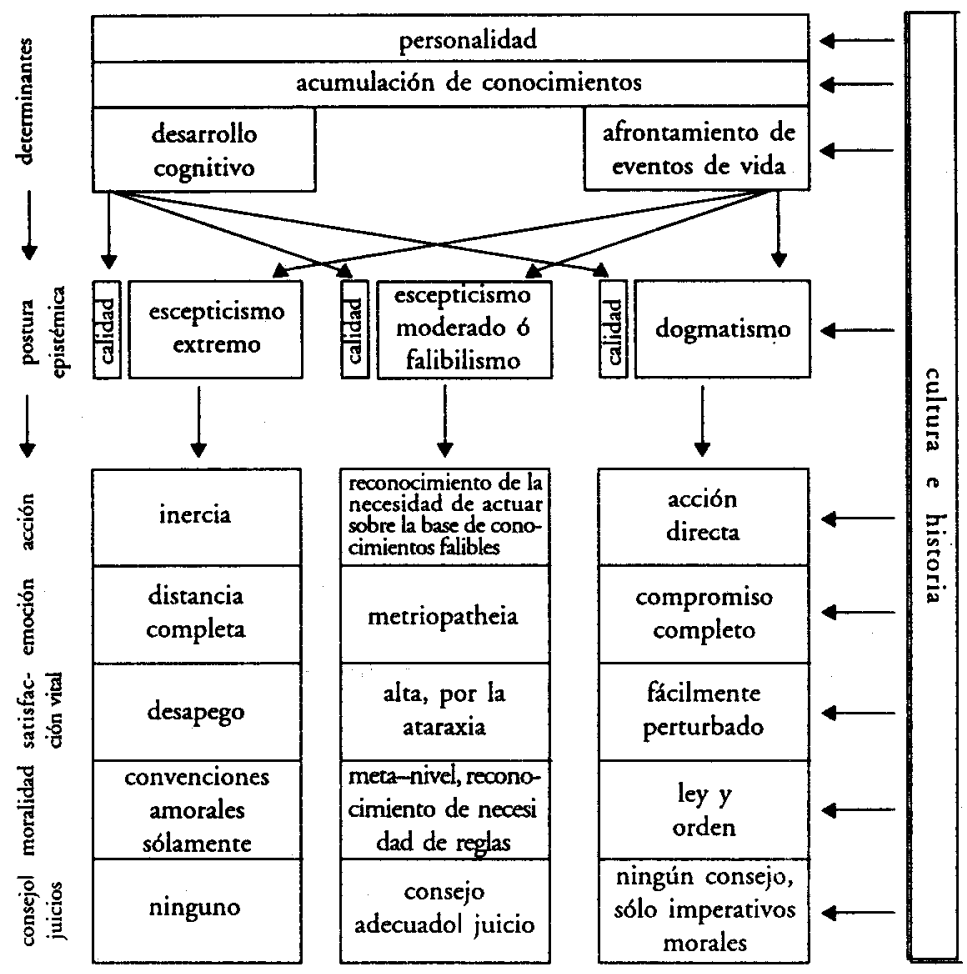


Así, los factores de personalidad (McCrea \& Costa, 1987) podrían predeterminar una postura epistémica. El afrontamiento de los eventos de vida y la acumulación de conocimientos impulsan la aparición de esta postura al ocasionar un desequilibrio epistemológico y conducir luego a un nuevo equilibrio. La acumulación de conocimientos y el desarrollo cognitvo determinan la calidad o profundidad de esta postura epistémica; es decir, el escepticismo moderado o falibilismo. Ella determina el modo específico en que uno actúa, la disposición emocional de uno, la satisfacción de vida, el nivel de argumentación moral y la naturaleza del consejo dado a otros. Todos los elementos están influidos por el contexto histórico/ cultural específico. Estará claro que queda mucho por hacerse todavía para probar este modelo.

Las siguientes sugerencias para la investigación futura podrían ser de utilidad:

- La investigación sobre sabiduría puede beneficiarse del material autobiográfico (estudios $n=1$, con el empleo de diarios estructurados y/o entrevistas de líneas de vida) para mejorar la validez ecológica de la teorización y de la investigación. Sólo estudiando la vida de los individuos podemos rastrear los cambios dinámicos en la resolución de problemas existenciales a lo largo de la vida. Un tema importante al respecto es el estudio del significado de la vida; es decir, la manera en que las personas estructuran sus vidas.

- Se necesita más investigación de carácter longitudinal puesto que la sabiduría está fuertemente influida por el Zeitgest (el espíritu del tiempo); la investigación transversal resulta una fuente no confiable de información.

- Para obtener más información sobre la dinámica de los cambios, se necesita investigación sobre los efectos de los eventos de vida en el nivel epistémico de uno.

- Para construir un sistema nomológico en torno a la sabiduría es necesario investigar las relaciones entre sabiduría y variables como moralidad y satisfacción de vida (ver Brugman, 1994b). 
- Como la sabiduría está ubicada en el nexo de diversas disciplinas, se requiere más cooperación entre filósofos, antropólogos e historiadores.

En realidad, tomará algún tiempo antes que el “idiotia” de Nicolás de Cusa logre estar satisfecho y que el libro fundamental de la sabiduría en su forma pura sea publicado. Hablando francamente, siento que esto no ocurrirá en mucho tiempo. En verdad, la sabiduría es sólo una meta asintótica (Burger, 1990; Platón, El Fedón, 101d-e, 107b) o como se dijo antes en relación a la verdad, un movimiento en dirección de un horizonte hipotetizado.

\section{Referencias}

Aristotle (1994). Rhetorica. Londres: Loeb.

Arlin, P.K. (1975). Cognitive development: A fifth stage? Developmental Psychology, 2, 602-606.

Assmann, A. (1990) (Ed.). Weisheit; Archäologie der literarischen Kommunikation III. Munich: Wilhelm Fink Verlag.

Assmann, A. (1994). Wholesome knowledge: Concepts of wisdom in a historical and cross-cultural perspective. In: D.L.Featherman, R.M. Lerner \& M.Perlmutter (Eds.), Life-Span Development \& Behavior, vol.12, pp.188-224. Hillsdale NJ: Lawrence Erlbaum Ass., Publ.

Ayer, A.J. (1971). The problem of knowledge. Harmondsworth: Penguin Books Ltd.

Bacon, F. (1642). De verulamio historia regni Henrici septimi. Leyden: Franc.Hackium.

Baltes, P.B. (1987). Theoretical propositons of life-span developmental psychology: on the dynamics betweengrowth and decline. Developmental Psychology, 23 (5), 611-626.

Baltes, P.B. (1994). Weisheit als Gegenstand psychologischer Forschung. Berlin: Max Planck Institut für Bildungsforschung.

Baltes, P.B. \& Smith, J. (1990). Weisheit und Weisheitsentwicklung: prolegomena zu einer psychologischen Weisheitstheorie. Zeitschrift 
für Entwicklungspsychologie und Pädagogische Psychologie, 22 (2), 95135.

Baltes, P.B., Staudinger,U.M., Maercker,A. \& Smith,J. (1995). People nominated as wise: A comparative study of wisdom-related knowledge. Psychology \& Aging, 10 (2), 155-166.

Berkeley, G. (1982/1710). A treatise concerning the principles of human knowledge. Ed.: K.Winkler. Indianapolis/Cambridge: Hacket Publ. Comp.

Birren, J.E. \& Fisher, L.M. (1990). The elements of wisdom: overview and integration. En: R.J. Sternberg (Ed.). Wisdom, its nature, origins, and development, Cambridge: Cambridge University Pres, pp. 317332.

Birren, J.E. \& Schaie, K.W. (1996)(Eds.). Handbook of the psychology of aging. 4ta. ed. San Diego: Academic Press.

Blanchard-Fields, F, Jahnke, H.C. \& Camp, C. (1995). Age differences in problem-solving style: the role of emotional salience. Psychology \& Aging, 10 (2), 173-180.

Brandstädter, J. \& Baltes-Götz, B.(1993). Personal control over development and quality of life perspectives in adulthood. En: P.B.Baltes \& M.M.Baltes (Eds.). Succesful aging: perspectives from the behavioral sciences, Cambridge: Cambridge University Press, pp.197-224.

Brandstädter, J, Wentura, D, \& Greve, W. (1993). Adaptive resources of the aging self: outlines of an emergent perspective. International Journal of Behavioral Develoment, 16 (2), 323-349.

Brugman, G.M. (1993). De wijze oudere onder psychogerontologisch spervuur. Psychologie \& Maatschappij, 62, 107-109.

Brugman, G.M. (1994a). Wisdom as high level epistemic cognition \& aging: A developmental task analysis. En: J.ter Laak, A.Podolskii \& P.G.Heymans (Eds.). Developmental Tasks: Towards a cultural analysis of human development. Dordrecht: Kluwer Academic Publishers. Brugman, G.M. (1994b). Moraliteit en wijsheid op latere leeftijd. En: T. Olthof \& D. Brugman (Eds.). Het ontstaan van moreel besef, Lisse: Swets \& Zeitlinger, pp. 249-270. 
Brugman, G.M. (1995). Autobiography and self in Russia and Holland: a qualitative analysis. Presentation Desna Conference. Moscú Russia. Brugman, G.M. \& Heymans, P.G. (1994). Psycho-gerontologie; een levensloopbenadering. Bussum: Coutinho.

Burger, R. (1990). Wisdom, philosophy, and happiness: on book X of Aristotle's Ethics. En: J.J.Cleary \& D.C.Shartin (Eds.). Proceedings of the Boston area Colloquium in ancient philosophy, vol.VI, Lanhan: University Press of America, pp. 289-307.

Burnyeat, M. (1983)(Ed.). The sceptical tradition. Berkley: University of California Press.

Camp, C.V. (1985). Wisdom and the feminine in the book of proverbs. Bible and literature studies, 11. Sheffield, UK: Almond, JSOT Press.

Canetti, Elias (1994). Het pantheon van vergeten dingen. Amsterdam: Arbeiderspers.

Chandler, M, \& Boutilier, R. (1992). The development of dynamic system reasoning. Human Development, 35, 121-137.

Cicero (19). Academica I \& II. Londres: Loeb

Cioran, E.M. (1995). Euvres. París: Éditions Gallimard.

Clayton, V. \& Birren, J.E. (1980). The development of wisdom across the life-span: a reexamination of an ancient topic. En: P.B. Baltes \& O.G.Brim (Eds.). Life-Span Development and Behavior, vol. 3, pp.103-135. Nueva York: Academic Press.

Cohen, S.M., Curd, P. \& Reeve, C.D.C. (1995)(Eds.). Readings in ancient Greek philosophy from Thales to Aristotle. Indianapolis/Cambridge: Hacket Publ.Comp.

Commons, M.L., Armon, C., Kohlberg, L., Richards, F.A., Grotzer, T.A. \& Sinnott, J.D. (Eds.) (1990). Adult Development, vol. 2. Models and methods in the study of adolescent and adult thought. Nueva York: Praeger.

Copleston, F. (1993). A history of philosophy. Vol.II. Medieval philosophy.

Fron Augustine to Duns Scotus. Nueva York: Image Books, Doubleday. Cropper et al. (1977). The relation between formal operations and a possible fifth stage of cognitive development. Developmental Psychology. Cusa, Nicolaus de (1988-1450). Idiotia de sapientia. Hamburgo: Felix Meiner Verlag GmbH. 
Denney, N.W. (1995). Critical thinking during the adult years: has the developmental functiion changed over the last four decades? Experimental Aging Research, 21, 191-207.

Diogenes Laërtius (1989). Leven en leer van beroemde filosofen. transl.: R.Ferwerda \& J.Eykman. Baarn: Ambo.

Dittmann-Kohli, F. (1984). Weisheit als mögliches Ergebnis der Intelligenzentwicklung im Erwachsenenalter. Sprache \& Kognition, 2, 112-133.

Dittmann-Kohli, F. (1990). The construction of meaning in old age: Possibilities and constraints. Ageing \& Society, 10, 279-294.

Dittmann-Kohli, F. (1995). Das persönliche Sinnsystem. Göttingen: Hogrefe. Emerson, R.W. (1900). Compensation. Nueva York: Caldwell.

Everson, S. (Ed.)(1990). Epistemology. Companions to ancient thought 1. Cambridge: Cambridge University Press.

Gatz, M. \& Karel, M.J. (1993). Individual change in perceived control over 20 years. International Journal of Behavioral Develoment, 16(2), 305-322.

Gent, (1966). Der Begriff der Weisen. Zeitschrift für Philosophische Forschung, $20(1), 77$.

Hankinson, R.J. (1995). The Sceptics. Londres/Nueva York: Routledge. Henkel, A. \& Schöne, A. (Eds.)(1967) Emblemata. Handbuch zur Sinnbildkunst des XVI. und XVII. Jahrhundert. Stuttgart: J.B. Metzlersche Verlagsbuchhandlung.

Heymans, P.G. \& Brugman, G.M.(1995). Talent, plasticity and ageing. En: J.Freeman, P.Span, \& H.Wagner (Eds.). Actualising Talent. Londres: Cassell.

Holliday, S.G. \& Chandler, M.J. (1986). Wisdom: Explorations in adult competence. Basel: Karger.

Honderich, T. (1995). The Oxford companion to philosophy. Oxford: Oxford University Press.

Hume, D. (1974/1777). Enquiries concerning buman understanding and concerning the principles of morals. Ed.: P.H.Nidditch. Oxford: Clarendon Press.

Kallio, E., \& Helkama, K. (1991). Formal operations and postformal reasoning: A replication. Scandinavian Journal of Psychology, 32, 18-21. 
Kitchener, K.S. (1983). Cognition, Metacognition, and Epistemic Cognition, Human Development, 26, 222-232.

Kitchener, K.S., King, P.M., Wood, P.K., \& Davidson, M.L. (1989).

Sequentiality and consistency in the development of reflective judgment: A six-year longitudinal study. Journal of Applied Developmental Psychology, 10, 73-95.

Kitchener, K.S., Lynch, C.L., Fischer, W., \& Wood, P.K. (1993). Developmental range of reflective judgment: the effect of contextual supportand practice on developmental stage. DevelopmentalPsychology, 29, 893-906.

Kohlberg, L. \& Clark Power (1981). Moral stages and problems beyond justice. Moral development, religious thinking, and the question of a seventh stage. Moral development and tragedy. En: L.Kohlberg (Ed.) The Philosophy of Moral Judgment. Moral stages and the idea of justice. Essays on moral development, vol.1.pp.307-399. San Francisco: Harper \& Row.

Kramer, D.A. (1983). Post-formal operations? A need for further conceptualization. Human Development, 26, 91-105.

Labouvie-Vief, G. (1985). Intelligence and cognition. En: J.E.Birren \& K.W.Schaie(Eds). Handbook of the psychology of aging,2nd ed., pp.500530. Nueva York: Van Nostrand Reinhold.

Labouvie-Vief, G. (1992). A neo-Piagetian perspective on adult cognition. En: R.J. Sternberg \& J.Smith (Eds.). Intellectual development. pp. 1972328. Cambridge: Cambridge University Press.

Lehrer, K. (1990). Theory of Knowledge. Londres: Routledge.

Linn, M., \& Siegel, H.(1984). Postformal reasoning: A philosophical model.

En: M. Commons, F. Richards, \& C. Armon (Eds.), Beyond formal operations, pp.239-257. Nueva York: Praeger.

Long, A.A. (1986). Hellenistic philosophy; stoics, epicureans, sceptics. Avon: Bath Press.

Long, A.A. \& Sedley, D.N. (1992). The Hellenistic Philosophers. Cambridge: Cambridge University Press.

Lourenço, O. \& Machado, A. (1996). In defense of Piaget's theory: A reply to 10 common criticisms. Psychological Review, 103 (1), 143-164. 
Maercker, A. \& Smith, J. (1991). Weisheit am Beispiel menschlicher Grenzsituationen. Poster vorgestellt auf der 10. Tagung für Entwicklungs-psychologie, Colonia 23-25 setiembre 1991.

Marcel, G. (1965). Le déclin de la sagesse. París: Plon.

Marquart, O. (1986). Zeitalter der Weltfremdheit? Beitrag zur Analyse der Gegenwart. En: Apologie des Zufälligen. Philosophische Studien, 7697. Stuttgart: Ph.Reclam.

Martelaere, P. (Ed.)(1996). Het dubieuze denken; geschiedenis en vormen van wijsgerig scepticisme. Kampen: Kok Agora.

McCrea, R., \& Costa, P. (1987). Personality in adulthood. Nueva York: The Guilford Press.

McKirahan, R.D. (1994). Philosophy before Socrates. Indianapolis/ Cambridge: Hacket Publ. Comp.

McLerran, J. \& McKee, P. (1991). Old age in myth and symbol. Westport: Greenwood Press.

Meacham, J.A. (1983). Wisdom and the context of knowledge: Knowing that one does not know. Contr.Human Development, 8, 111-134. Basel: Karger.

Meacham, J.A. (1990). The loss of wisdom. En: Sternberg, R.J.(Ed.). Wisdom, its nature, origins, and development, pp. 181-211, Cambridge: Cambridge University Press.

Mergler, N.L. \& Goldstein, M.D.(1983). Why are there old people. Human Development, 26, 72-90.

Montaigne, M.de, (1991; 1580). The Complete Essays. (M.A. Screech Ed.) Harmondsworth: Penguin Books Ltd.

Multatuli (1973). Volledige Werken.(Complete Works) Amsterdam: Van Oorschot.

Murray, K. (1985). Life as fiction. Journal for the Theory of Social Behaviour, 15, 173-188.

Musgrave, A. (1993). Common sense, science and scepticism.Cambridge: Cambridge University Press.

Nietzsche, F. (1972). Wissenschaft und Weisheit im Kampfe. F.Nietzsche Werke Bd.III,p.1041-1056. Frankfurt/M: Verlag Ullstein GmbH.

Norton, D.F.(1993). The Cambridge Companion to Hume. Cambridge: Cambridge University Press. 
Oelmüller, W.(1989)(Ed.). Philosophie und Weisheit, Kolloquien zur Gegenwartsphilosophie. Bd.12. Paderborn: F.Schoeningh.

Olejnik, M., \& Niemczyñski, A. (1993). The influence of the tasks content within the pragmatics of life on the cognitive perspective in which is is viewed. Cracow: Jagiellonian University. Internal publication.

Olson, E. (1966). Tragedy and the theory of drama. Detroit: Wayne State University Press.

Orwell, L. \& Achenbaum, A. (1993). Gender and the development of wisdom. Human Development, 36, 274-296.

Pascual-Leone, J. (1984). Attentional, dialectic, and mental effort: Towards an organismic theory of life stage. In: M.L.Commons, F.A.Richards, \& C.Armon (Eds.), Beyond Formal Operations, pp.182-215, Nueva York: Praeger.

Pratt, M.W. \& Norris, J.E. (1994). The social psychology of aging. Oxford: Blackwell.

Quevedo, F. de (1992; 1612). Dromen, Baarn: Ambo.

Riegel, K.F. (1973). Dialectic operations: the final period of cognitive development. Human Development, 16, 346-370.

Rondhuis, T. (1994). Filosoferen met kinderen. Rotterdam: Lemniscaat. Rondhuis, T. (1996). Protocols of young adolescents talking about truth. (sin publicar).

Rüdiger, H. (Ed.)(1965). Briefe des Altertums. Zürich/Stuttgart: Artemis Verlag.

Salthouse, T.A. (1991). Theoretical Perspectives on Cognitive Aging. Hillsdale N.J.: Lawrence Erlbaum Ass., Publ.

Schlegel, F.(1978)(1798). Kritische und theoretisch Schriften. Stuttgart: P.Reclam Jun./ ${ }^{*}$ Charakteristiken und Kritiken I (1796-1801). in Eichner, H.(Red.) Kritische Friedrich Schlegel Ausgabe, Bd.II,1967. Munich/Paderhorn/Viena: Schöningh.

Schopenhauer, A. (1851; 1976). Aphorismen zur Lebensweisheit. Frankfurt am Main: Insel

Schroots, J.J.F. (1995). Psychological models of aging. La Revue Canedienne $d u$ Vieillissement, 14 (1), 44-66.

Seligman, M.E.P. \& Maier, S.F.(1967). Failure to escape traumatic shock. Journal of Experimental Psychology, 74 (1), 1-9. 
Seneca, L.A. (1996). Dialogen. Amsterdam/Meppel: Boom.

Sextus Empiricus (1994). Outlines of scepticism. Transl. J.Annas \& J. Barnes. Cambridge: Cambridge University Press.

Sinnott, J.D. (1984). Postformal reasoning: the relativistic stage. En: M.L.

Commons, F.A.Richards, \& C.Armon (Eds.). Beyond Formal Operations, p.298-325. Nueva York: Praeger.

Sinnott, J.D. (1993). Commentary. Human Development, 36, 297-299.

Sowarka, D. (1989a). Weisheit im Kontext von Person, Situation und Handlung. Studien und Berichte 48, Berlín: Max-Planck-Institut für Bildungsforschung.

Sowarka, D. (1989b). Weisheit und weise Personen: Common-SenseKonzepte älterer Menschen. Zeitschrift für Entwicklungspsychologie und Pädagogische Psychologie, 21 (2), 87-109.

Staudinger, U.M. (1989). The study of life review. An approach to the investigation of intellectual development across the life span. Studien und Berichte 47. Berlín: Max-Planck-Institut für Bildungsforschung. Staudinger, U.M. (1990). Lebensrückblick: ein Weg zur Weisheit? Psychologie Heute, März, 60-63.

Sternberg, R.J. (1985). Implicit theories of intelligence, creativity, and wisdom. Journal of Personality and Social Psychology, 49, 607-627.

Sternberg, R.J. (1990)(ed.). Wisdom; its Nature, Origin, and Development.

Cambridge: Cambridge University Press.

Strawson, P.F. (1985). Skepticism \& Naturalism. Some varieties. Londres: Methuen \& Co.

White, R. (1959). Motivation reconsidered: The concept of competence. Psychological Review, 66, 297-333.

Wittgenstein, L. (1969). Über Gewissheit/On certainty. Ed.: G.Anscombe \& G.von Wright. Transl.: D.Paul \& G.Anscombe. Oxford: Basil Blackwell.

Woodruff, P.(1988). Aporetic Pyrrhonism. Oxford Studies in Ancient Philosophy. 6, 139-168. 